\title{
MUTACIONES DE LOS USOS DEL AGUA EN LA AGRICULTURA ESPAÑOLA DURANTE LA PRIMERA DÉCADA DEL SIGLO XXI ${ }^{1}$
}

\author{
Alfredo Morales Gil \\ María Hernández Hernández \\ Instituto Interuniversitario de Geografía \\ (Universidad de Alicante)
}

\section{RESUMEN}

El análisis de la dinámica de cambio de los regadíos españoles en la primera década del siglo XXI es el objetivo de esta investigación. Éstos se caracterizan, grosso modo, por un continuo incremento de la superficie y la implantación de la modalidad de riego localizado. Éste aumento, a diferencia de décadas anteriores, se debe en gran medida a la expansión que han registrado las superficies ocupadas por olivar, viñedo y algunos cereales, cultivos tradicionalmente de secano, en comarcas que, con anterioridad a estas fechas, no tenían tradición en las prácticas del regadío, frente a la atonía de aprovechamientos como hortalizas o ciertos frutales.

Palabras clave: Regadío, usos del agua, agricultura, siglo XXI.

\section{ABSTRACT}

The analysis of Spanish irrigated land dynamic of change in the first decade of the $21^{\text {st }}$ century is the aim of this research. These are characterized by a continuous increase of this surface and the introduction of located irrigation. This increase, unlike previous decades, is owed to the expansion that have registered the surfaces occupied by olive groves and vineyards and some cereals, crops traditionally of dry land agriculture, in regions that, before these dates, they did not have tradition in the practices of irrigation, opposite to the atony of crop as vegetables or certain fruit trees.

Key words: Irrigated land, water uses, agriculture, 21st century.

1 Este artículo se inserta en el Proyecto de investigación «Modelos de desarrollo territorial y tipologías de consumo de agua potable en espacios turístico residenciales del litoral alicantino» (CSO2009-12772-C03-03) financiado por el Ministerio de Ciencia y Tecnología. 


\section{Introducción}

En la segunda mitad del siglo XX, se produjeron una serie de modificaciones sustanciales en el uso agrícola del agua en España, no sólo cuantitativamente sino también cualitativamente. Así, se pasó de unas 1.450.000 hectáreas regadas en 1950 a unas 3.177 .900 en 1995 (MAPA, 1999). Superficie de regadío, esta última, que fue considerada como la máxima que se podía alcanzar con las disponibilidades hídricas reguladas; pero, sorprendentemente, los datos más recientes del Ministerio de Medio Ambiente y Medio Rural y Marino (MARM, 2009) nos indican que el incremento de las superficies irrigadas continúa; cifrándose éste, según fuentes oficiales, en alrededor de 500.000 hectáreas. Este último proceso expansivo, además, se produce durante el periodo en que más se ha criticado el uso desmedido del recurso agua en agriculturas con escasas repercusiones socio-económicas reales sobre las comarcas afectadas y que, al mismo tiempo, contribuyen a incrementar la presión sobre los recursos hídricos disponibles de algunas regiones, que se caracterizaban por marcadas tendencias hacia su agotamiento.

No sólo se amplía la superficie de regadío durante esta última década, sino que se producen, también, variaciones en cultivos y modalidades de riego. Los cambios en los aprovechamientos se deben, por un lado, a la incidencia de la PAC, y, de otro, a la demanda de frutas y hortalizas extratempranas desde los mercados europeos, básicamente. Así, ciertos cultivadores de herbáceos vieron como, con el aumento de la producción, incrementaban el monto de la subvención a recibir, lo que estimuló la puesta en regadío de áreas que, hasta entonces, se habían mantenido con un cultivo pluvial tradicional. Otras veces, fueron los exportadores hortofrutícolas de las regiones de Valencia, Murcia y Andalucía los que advirtieron las posibilidades de obtener cosechas rentables primaverales e incluso veraniegas en las comarcas de transición, desde las tradicionales costeras mediterráneas a las de climas continentales interiores. De esta forma, lechuga, brócoli, melón y algunas variedades de prunus ocuparon tierras de cultivo en secano hasta entonces. Asimismo, en las últimas décadas del siglo XX, se empieza a implantar el riego localizado en cultivos leñosos, que hasta esos años apenas se regaban como eran el olivar y viñedo, que, unas veces legalizados y otras disponiendo de caudales obtenidos subrepticiamente, comienzan a demandar grandes volúmenes de agua en el verano. A finales de 2009, según estadísticas oficiales, se riegan alrededor de 346.670 hectáreas de viñedo para vinificación y 689.267 hectáreas de olivar (MARM, 2009), frente a los datos de 1995 en que sólo se beneficiaban unas 62.000 y 200.000 hectáreas, respectivamente (MAPA, 1999).

Otro cambio cualitativo significativo ha afectado a la tipología de regadío. En 2009, la superficie regada por goteo se situaba en torno al $50 \%$ del total, frente al $22 \%$ de mediados de los noventa. Su expansión se vincula a un doble proceso. Por un lado, los diferentes programas de modernización de regadíos tradicionales que, auspiciados desde diferentes administraciones públicas, se han orientado a la sustitución del regadío a manta por estos sistemas de manejo de agua. Por otro, estas tecnologías se asociaron, a las nuevas transformaciones en regadío, especialmente en el sector mediterráneo. Se ha pasado de 715.00 hectáreas en 1995 a unas 914.112, según el Censo Agrario de 1999, y a casi 1.600.000 ha., según la última encuesta publicada sobre Superficies y rendimientos agrícolas (ESYR$\mathrm{CE}$ ). Tanto en cultivos leñosos como en hortícolas se ha impuesto en toda España el riego localizado por goteo. Hoy en día, están utilizando esta modalidad de riego un porcentaje muy elevado de los cítricos, prunus, hortalizas y gran parte del olivar y del viñedo. Teóricamente, es muy eficiente en el ahorro de agua por unidad de superficie. Siendo éste uno de los principales argumentos esgrimidos para su difusión. Sin embargo, su tecnología permite conducir volúmenes hídricos a lugares alejados de su tradicional uso por gravedad, 
así como utilizar directamente los recursos hipogeos de las comarcas de implantación, sin necesidad de hacer grandes transformaciones de los parcelarios. Estas particularidades han permitido, por un lado, la ampliación de la superficie a cultivar y, por otro, favorecer el desvío y conducción de caudales fuera de los ámbitos naturales en donde se asentaban los regadíos (fondo de valle). Dinámica ésta que ha agravado la presión sobre los recursos subterráneos, acentuando los procesos de sobreexplotación.

A esta situación actual del regadío español, se ha llegado por la vía de la ausencia de una política centralizada de coordinación de los usos del agua y de su incidencia socioeconómica de conformidad con la PAC y las diferentes reformas auspiciadas desde principios de los noventa y la Directiva Europea del Agua (DMA). Ministerios y Comunidades Autónomas han ido diseñando y, sobre todo, aplicando aquellas políticas que consideran que se adecuan mejor a sus intereses políticos. Así, unas actuaciones propugnaban la expansión del regadío para poder acogerse a las subvenciones de la PAC. Otras, apostaban por el incremento de producciones y fomentaban su difusión en el olivar y el viñedo. Y otras, finalmente, únicamente se preocuparon por favorecer la mejora de sus regadíos sin inquietarse por su rentabilidad, a pesar de que la demanda en los mercados exteriores se reducía, caso de los cítricos, viñedo y olivar. Se llega, de este modo, a obtener cosechas récords que tienen imposible salida en los mercados, tal como está sucediendo con los excedentes de naranjas, limones, aceite y vino, entre otros. Proceso que se traduce en una importante caída en los precios percibos por los productores, que en ocasiones llegan a situarse próximos a los costes de producción, cuando no se sitúan por debajo. Además, estos cultivos vienen en los últimos años necesitando cada vez menos mano de obra, gracias a las nuevas tecnologías de cultivo, por lo que están perdiendo parte de su trascendencia social.

Las políticas al respecto son erráticas y descoordinadas y en ningún caso responden al discurso conservacionista sobre el uso del agua y mucho menos a las directivas de la UE. Así, asistimos, por ejemplo, a la expansión del regadío localizado del viñedo en espaldera con ayudas de las Comunidades Autónomas, que aumenta considerablemente la producción de vino, cuando su consumo disminuye y la UE prima su arranque, a fin de reducir el volumen de stocks, que está hundiendo en la miseria a los agricultores tradicionales. Éstos, además, se ven abocados a solicitar ayudas a las administraciones para la compra de excedentes destinados a su destilación por las alcoholeras, para aminorarlos en parte; lo que conduce a una mayor reducción de sus ingresos. En definitiva, nos encontramos ante el planteamiento de una agricultura claramente subvencionada. A esta clara dependencia de las ayudas europeas se une otro factor, incluso más negativo, como es el hecho de que están consumiendo en exceso un recurso limitado: el agua, que provoca desequilibrios medioambientales de difícil corrección posterior, por no decir nula, y cuya extracción, en muchos casos, requiere gran cantidad de energía que hay que comprar, en gran medida, en los mercados internacionales, lo que acentúa la dependencia energética del país, a precios cada vez más elevados. Esto, sin entrar a valorar la incidencia en las emisiones de $\mathrm{CO}_{2}$.

Se impone, teniendo en cuenta, las consecuencias derivadas de unas actuaciones descoordinadas, la necesitad de implantar una política agraria estatal en la que los regadíos sean contemplados desde una perspectiva de eficiencia en su doble vertiente, económica y social, que provoque el menor impacto medioambiental y que sea respetuosa con las directrices europeas, tanto las referentes a la PAC, como con el medio natural y las de gestión de recursos hídricos. A este respecto, se tendrá que apostar por una ordenación de cultivos en regadío consecuente con lo indicado anteriormente y que tenga en cuenta su repercusión social. En esta línea, en aquellas comarcas que vieran peligrar el sector agrícola tradicional por su baja rentabilidad, se deberían destinar ayudas comunitarias a aquellos agricultores con cultivos pluviales y que realmente dependan de estos ingresos, en detrimento de los 
grandes cultivadores extensivos, que en la actualidad acaparan más del $80 \%$ de las ayudas de la PAC y cuyos beneficios no repercuten sobre el medio rural. Así, preservaríamos el recurso agua y la afección medioambiental disminuiría, al tiempo que nuestro costo energético se reduciría, al consumir menos energía, tanto en la tecnología del regadío como en el resto de la praxis de los diferentes cultivos.

Estas premisas se basan en el análisis de fuentes estadísticas sobre superficies, aprovechamientos y modalidades de regadío elaboradas tanto por el gobierno central como por las consejerías de las comunidades autónomas. Éstas se complementan con la consulta de las iniciativas, adoptadas por diversas administraciones, orientadas al fomento y modernización de regadíos y el trabajo de campo. La consulta de estas fuentes y, sobre todo, la comparación de unas y otras trata de solventar una de las debilidades evidenciadas en el análisis de las fuentes estadísticas como es su no actualización, especialmente, en aquellos cultivos con un importante incremento en los últimos años, como pone de manifiesto el trabajo de campo o las entrevistas a actores sociales afectados. Pero, también, las contradicciones que se evidencia con la consulta de datos proporcionados por diferentes administraciones, por ejemplo, nacional y comunidad autónoma, pero también en los elaborados por una misma administración.

\section{El regadío en la primera década del siglo XXI, la continuidad de una tendencia alcista}

Las tierras cultivadas en la primera mitad del siglo XXI han registrado una retracción. Esta tendencia se inserta en el abandono de superficies que caracterizaban a los diferentes países desarrollados desde mediados del siglo XX, como resultado de la conjunción de diversos procesos. De un lado, el abandono de terrazgos de escasa vocación agrícola o marginales y, de otra, la competencia que sobre ellos ejercen los usos urbanos e industriales. Estas causas se vieron acentuadas por la fragmentada estructura parcelaria, el envejecimiento de los activos, la debilidad de los canales de comercialización o la escasez de recursos hídricos, que complican notablemente el mantenimiento de unas actividades, las agrarias, dada su moderada rentabilidad y la falta de expectativas para continuar con su práctica. En el periodo comprendido entre 1990 y 2007, se abandonaron alrededor de 2,7 millones de hectáreas (figura 1). Esta dinámica regresiva enmascara una realidad dual. Es el secano el que ha registrado la mayor reducción de las áreas cultivadas, al pasar de aproximadamente unos 17 millones de hectáreas, a poco más de 13,7 dada la aleatoriedad de las cosechas y su baja rentabilidad. Frente a esta disminución en los cultivos pluviales, las superficies regadas se ampliaron en casi 500.000 hectáreas.

El aumento del regadío continúa siendo en ámbitos mediterráneos la opción elegida para intensificar la actividad agraria, ya que permite incrementar la productividad al reducir la aleatoriedad del secano e introducir aprovechamientos hortícolas y frutícolas. En el pasado, su expansión fue considerada como una estrategia de desarrollo agrario con fondos públicos. Las grandes zonas regables de iniciativa pública, en sus diferentes versiones, desempeñaron un papel de «reforma agraria». En la actualidad, la modernización y consolidación de los terrazgos irrigados y la creación de otros nuevos, cuando las disponibilidades hídricas lo permiten, supone el establecer una política de mantenimiento de una agricultura viable y estratégica para el conjunto de la sociedad. Su importancia, no sólo, es macroeconómica, sino que, desde una óptica microeconómica, la transformación de secano a regadío ha supuesto para muchos agricultores la supervivencia económica. Para comprender su aportación, a nivel de las explotaciones agrarias, basta decir que, por término medio, una hectárea regada produce seis veces más que una de secano y genera una renta cuatro veces superior 


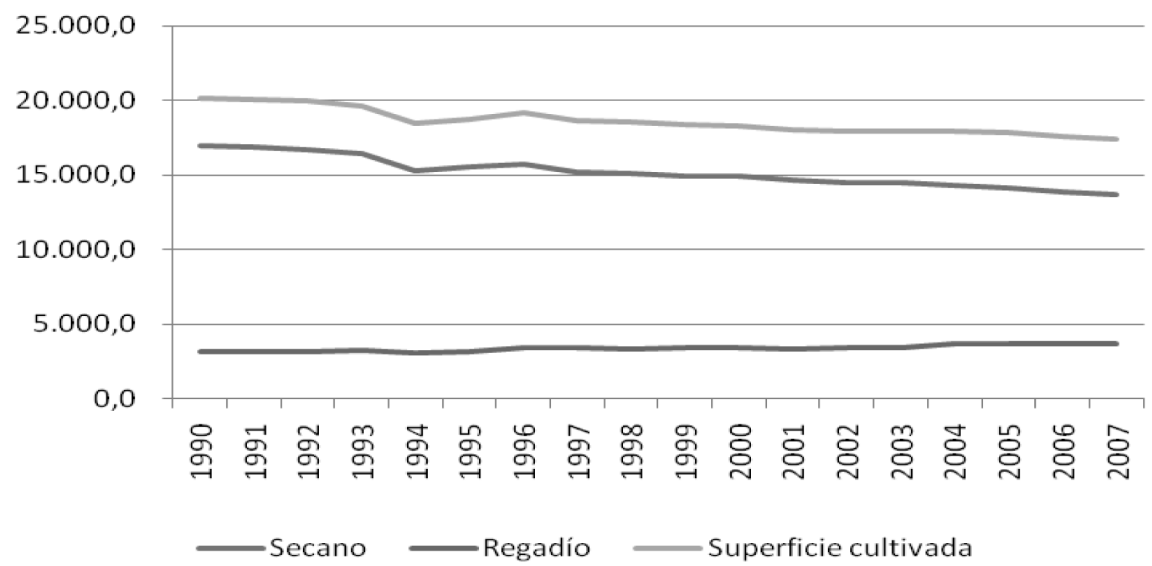

FIgURA 1. Evolución de las tierras de cultivo (miles de hectáreas) (1990-2007). Fuente: MAPA, 1991 y MARM, 2009. Elaboración propia.

(MAPA, 2003). A finales del siglo XX y principios del XXI, la creación de nuevos regadíos en Aragón, Castilla-León, Extremadura y Castilla-La Mancha sigue considerándose como una política de desarrollo rural, que permite incrementar la rentabilidad de la agricultura y, consiguientemente, fijar población en unas áreas donde los procesos de pérdidas demográficas han sido la dinámica dominante desde mediados del siglo XX. Significativo al respecto resulta el Plan Nacional de Regadíos, que contemplaba la creación de medio millón de nuevas hectáreas para el horizonte 2008 (MAPA, 2003: 226). En la misma línea, se sitúan las memorias de los Planes de Cuenca elaborados a mediados de los noventa en los que la génesis de nuevos regadíos, la consolidación de los existentes, especialmente mediante la satisfacción de las demandas agrícolas insuficientemente atendidas, y su modernización son temas prioritarios. El Esquema Provisional de Temas Importantes, elaborado por las diferentes Demarcaciones Hidrográficas a lo largo del 2009, reitera estas cuestiones, ampliando el horizonte hasta el 2015. Las referencias a la creación de regadíos como política de desarrollo rural son explícitas en los Esquemas de Temas Importantes de la Demarcación Hidrográfica del Duero y en la del Guadiana. Paradigmática resulta, en cambio, la del Júcar, en la que las tensiones por los usos del agua entre las Comunidades Autónomas de Castilla-La Mancha y la Valenciana se refleja en la desaparición de superficies de regadío, dada la metodología utilizada, en esta última.

La agricultura de regadío sigue siendo el sustento estructural y fundamental del sector agrícola. Según datos del Plan Nacional de Regadíos (2003), en España, sólo el 14,5\% de la superficie agraria es de regadío, pero aporta el 55\% de la Producción Agraria Nacional (PAN), generando un 30\% de los jornales estimados necesarios para el sector agrario, lo que puede representar unos 600.000 empleos teóricos (MAPA, 2003). Acentuándose su importancia, si se tiene en cuenta que la industria de alimentación está vinculada directamente, y en gran medida, a las producciones de regadío (conservas vegetales, zumos, harinas, azúcar, alimentación animal, etc.). Igualmente, al analizar la balanza agraria alimentaria se aprecia que las producciones típicas de regadío como las hortofrutícolas, influyen decisivamente en los saldos favorables de los intercambios comerciales. Según datos de 2008, el valor de la producción de la rama agraria ascendía a 41.744 millones de 
euros, del que aproximadamente el $62 \%$ correspondía a la producción vegetal (MARM, 2009: 1.064). De éste, los epígrafes hortalizas y frutas aglutinan los ingresos más elevados (7.438,3 y 7.209,7 millones de euros, respectivamente) frente a valores inferiores de aprovechamientos como los cereales (4.674 millones), el vino y mosto (1.120 millones) o el aceite de oliva (1.968,3 millones). Las exportaciones españolas de frutas y hortalizas a los mercados europeos alcanzaron ese mismo año un valor de 7.388 millones de euros, de los que unos 4.181 corresponden a las regiones de Valencia y Murcia. La Comunidad Valenciana lidera las exportaciones agrarias españolas, con más de 2.500 millones de euros, gracias a los envíos de cítricos y hortalizas, que representa algo más de un $56 \%$ de las exportaciones agroalimentarias de esta comunidad; porcentaje que se incrementa hasta el $70 \%$ en la región de Murcia (CREM, 2008).

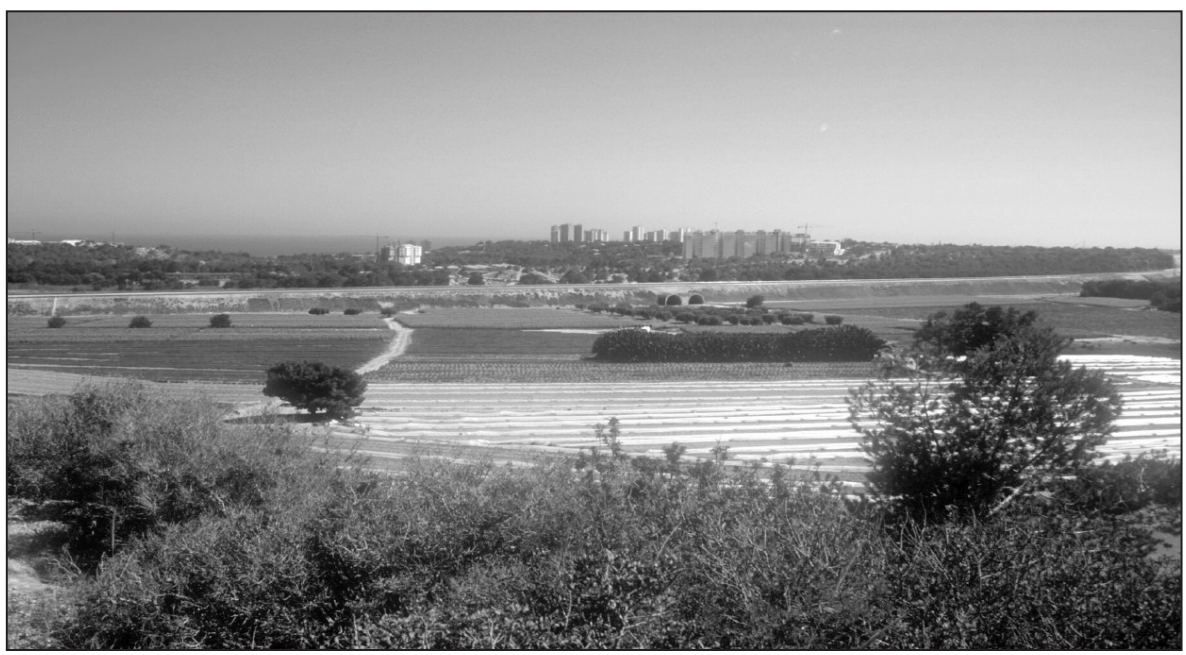

FIgURA 2. Litoral del municipio de Orihuela en las proximidades del río Nacimiento (provincia de Alicante), donde se observa una fuerte competencia entre las actividades turístico-residenciales y las agrícolas por los usos del agua y el suelo.

La expansión de las tierras regadas desde principios del siglo XX ha sido una constante, al amparo de las políticas conducentes a incrementar los caudales almacenados (construcción de embalses) y el impulso dado a las superficies abastecidas con aguas subterráneas durante las décadas de los años sesenta hasta los ochenta. Esta dinámica positiva no significa que en el periodo analizado no se hayan destruido terrazgos irrigados. Los regadíos históricos mediterráneos han visto como sus superficies se reducían considerablemente, a consecuencia de las fuertes presiones a los que están sometidos desde los años sesenta por los usos urbanos, como resultado, por un lado, del crecimiento de los núcleos de población que se ubican en sus proximidades y, por otro, la expansión turístico-residencial. Aquél al amparo de la llegada de población procedente de comarcas y regiones del interior de España atraída por el desarrollo industrial y de las actividades terciarias de algunas ciudades y áreas metropolitanas, que requerían abundante mano de obra. Éste, por la difusión de los usos 
turísticos y, sobre todo, los residenciales, dada la notable trascendencia que las actividades turísticas adquieren en el litoral mediterráneo y que ha significado la urbanización de notables superficies en las huertas de los municipios litorales. En esta situación, se encuentran los regadíos históricos del Júcar, Turia, Palancia, Mijares, Segura, Monnegre, entre otros. Paradigmática es la situación de la Huerta de Valencia, con unas 15.000 ha sometidas a fuerte presión urbanística por la expansión del área metropolitana, sobre todo en su zona sur y oeste, donde se ha destruido más del 75\% del regadío original existente (Rico y Hernández, 2008). La competencia que los usos turístico-residenciales ejercen sobre el recurso suelo y agua, sin olvidar la mano de obra, determinan la necesidad de una rentabilidad alta de las actividades agrarias que se practican en los municipios litorales mediterráneos, ya que en caso contrario, sucumben a la expansión residencial o se convierten en barbecho social en espera de obtener cuantiosas plusvalías mediante su conversión en suelos urbanizables (figura 2). Estas contracciones son compensadas por la conversión de antiguos secanos, en un primer momento en los sectores litorales y, posteriormente, en áreas interiores. De los regadíos históricos por gravedad de cursos con aguas perennes como el Mijares, Turia, Júcar y Segura se ha pasado, sobre todo a partir de la década de los años sesenta, a otros sistemas de derivación mediante potentes bombas que extraen las aguas de los ríos y de los acuíferos subterráneos, de las actuaciones hidráulicas como los trasvases Tajo-Segura y Júcar-Turia y obras de colonización auspiciadas por la administración (INC e IRYDA) y llevadas a cabo por sociedades agrarias de transformación, que han permitido captar aguas, elevarlas y conducirlas a terrenos muy alejados de los lechos de inundación para el riego de cítricos, frutales y hortalizas.

El regadío con unas 3.689.400 hectáreas en 2007 ocupaba alrededor del 21\% de las superficies cultivadas; cifras que ponen de manifiesto la importancia de la agricultura de tipo pluvial, dado el predominio de unos climas de filiación mediterránea, que se traducen, entre otros rasgos, en unas precipitaciones escasas y concentradas en el tiempo. No obstante, el incremento ha sido constante, al pasar de 15,8\% en 1990 al 21,2\% en 2007. Un estudio detallado de la estadística oficial elaborada por diferentes organismos (Ministerio de Agricultura y/o las Consejerías de Agricultura) muestra, en numerosas ocasiones, la no coincidencia de cifras e, incluso, contradicciones entre ellas. Ilustrativo resulta la comparación entre el Anuario de Estadística y la Encuesta sobre Superficies y Rendimientos Agrícolas (ESYRCE). Los datos ofrecidos por esta última sitúan la superficie regada en 3,3 millones de hectáreas, frente a una cifra ligeramente superior, según el Anuario de Estadística (3,6 millones). Si se comparan las cifras proporcionadas por ambas fuentes, una primera conclusión es la «pérdida de superficies» de la segunda con respecto a la primera y una posible inversión de la tendencia al crecimiento de las superficies regada. Esa diferencia, sin embargo, se debe en gran medida a la no coincidencia de cifras entre el Anuario de Estadística Agraria y la Encuesta sobre superficie y rendimientos de cultivos, ya que las dos muestran un incremento de las tierras irrigadas.

Esa disparidad de las fuentes se acentúa, en ocasiones, debido a su falta de actualización. Este proceso se intensifica, sobre todo, en aquellos aprovechamientos como son el olivar y el viñedo, que han registrado un intenso proceso de transformación en regadío en la última década. Las fuentes estadísticas, si bien, reflejan, esa dinámica alcista, las cifras que recogen son inferiores a las que pone de manifiesto el trabajo de campo, las entrevistas con sindicatos agrarios e, incluso, el estudio de las ayudas recibidas para la modernización de regadío y/o las ayudas estructurales, entre las que la introducción de sistemas de regadío con manejo de agua, resulta mayoritario. Obtener, por ejemplo, las cifras de olivar en regadío de fuentes diversas y compararlas, posteriormente, proporciona resultados, cuanto menos sorprendentes. La superficie regada en 1995 en Andalucía, según 
el Informe del sector olivarero andaluz ascendía a 297.434 ha (Conserjería de Agricultura, 2008:16); cifra que superaba las 199.857 hectáreas para toda España del Anuario Estadístico del Ministerio de Agricultura. Situación similar se observa al consultar las cifras relativas al viñedo proporcionadas por el Anuario Estadístico de Castilla-La Mancha, que las sitúa en 148.945 ha (Conserjería de Agricultura, 2008:50) frente a las 114.188 del Anuario del Ministerio de Agricultura.

El análisis de la evolución de las superficies regadas por regiones (figura 3) pone de manifiesto una serie de dinámicas heredadas, entre las que destaca la concentración del regadío en aquellas comunidades autónomas con climas de filiación mediterránea y en los que el regadío, desde época histórica, permitía aminorar la aleatoridad del secano. Una breve aproximación a escala regional evidencia una evolución dual en las tierras de regadío. Frente a unas comunidades que ven éstas incrementadas de manera significativa (Aragón, Castilla-La Mancha, Castilla y León y Andalucía), otras (Extremadura, Baleares y Comunidad Valenciana) las reducen. En esta última, la disminución de superficies regadas viene generada por una serie de factores. A la escasez de recursos hídricos, se unen problemas estructurales y, sobre todo, de rentabilidad en uno de los tradicionales aprovechamientos de regadío, los cítricos. Andalucía, Castilla-La Mancha, Castilla y León y Aragón acumulan el $67 \%$ de las superficies irrigadas frente al 62\% de 1996.

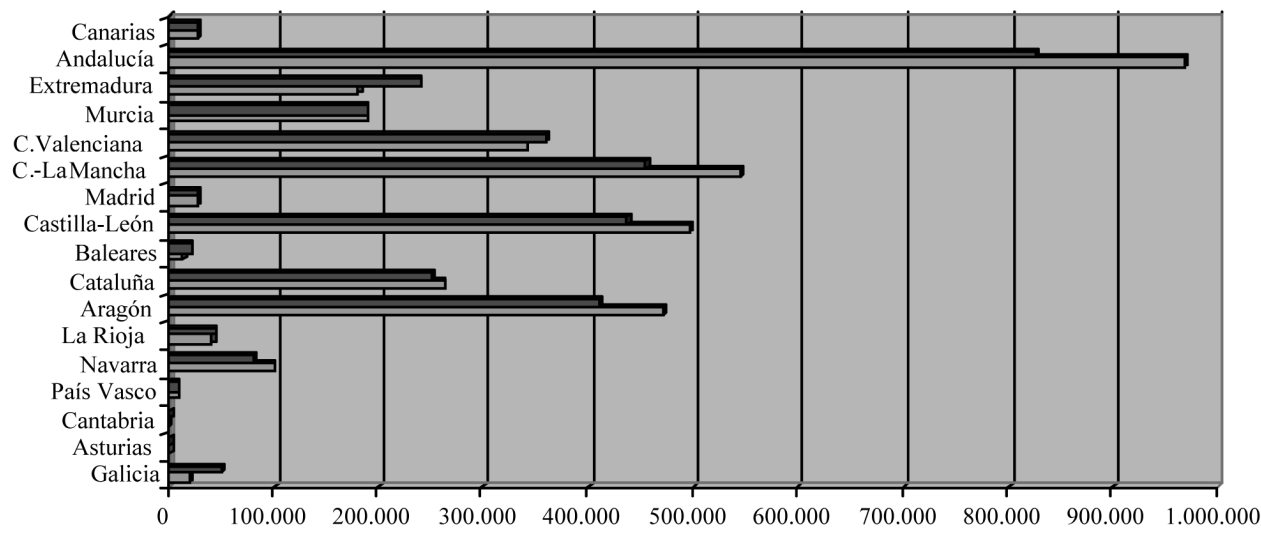

$\square 2007 \square 1996$

FIgura 3. Evolución de las superficies de regadío (ha) según Comunidades Autónomas (1996-2007).

Fuente: MAPA, 1999 y MARM, 2009. Elaboración propia.

\section{Evolución de los aprovechamientos, entre la atonía de los cultivos tradicionales de regadio y su expansión por las áreas de cultivos pluviales}

La tendencia general descrita en el epígrafe anterior registra una evolución diferenciada según los grupos de cultivo: los herbáceos se caracterizan por una marcada tendencia negativa, especialmente desde el año 2000, frente al incremento notable de los leñosos, que prácticamente han duplicado su superficie desde 1990 al pasar de 741.400 hectáreas a 
1.199.700 en 2007. Estos regadíos extensivos, basados en los aprovechamientos cerealícolas, forrajeros y los cultivos industriales, constituyen el sistema dominante, al concentrar casi el 55\% de las superficies regadas. Ésta se elevaría hasta prácticamente el 70\%, si no se contemplase las de barbecho (figura 4). Presentan, igualmente un nítido contraste con los denominados regadíos intensivos. Éstos últimos, que se concentran en un elevado porcentaje en el litoral mediterráneo comprendido entre la costa de Motril y el Delta del Ebro, se definen por los aprovechamientos practicados (hortofrutícolas), los sistemas de cultivo (invernaderos, sistemas de manejo de agua) y una marcada orientación exportadora (Morales, 1997). El predominio espacial de los cereales (unas 900.000 ha) con respecto a los cultivos hortícolas y frutícolas responde a limitaciones climáticas (en el caso de los regadíos interiores), pero no sólo a ellas. En el valle del Guadalquivir y en el Bajo Guadiana se relaciona con la existencia de grandes explotaciones, que se orientan hacia la maximización de los beneficios y la minimización del riesgo y, donde los cultivos subvencionados son la opción elegida (tabla 1).

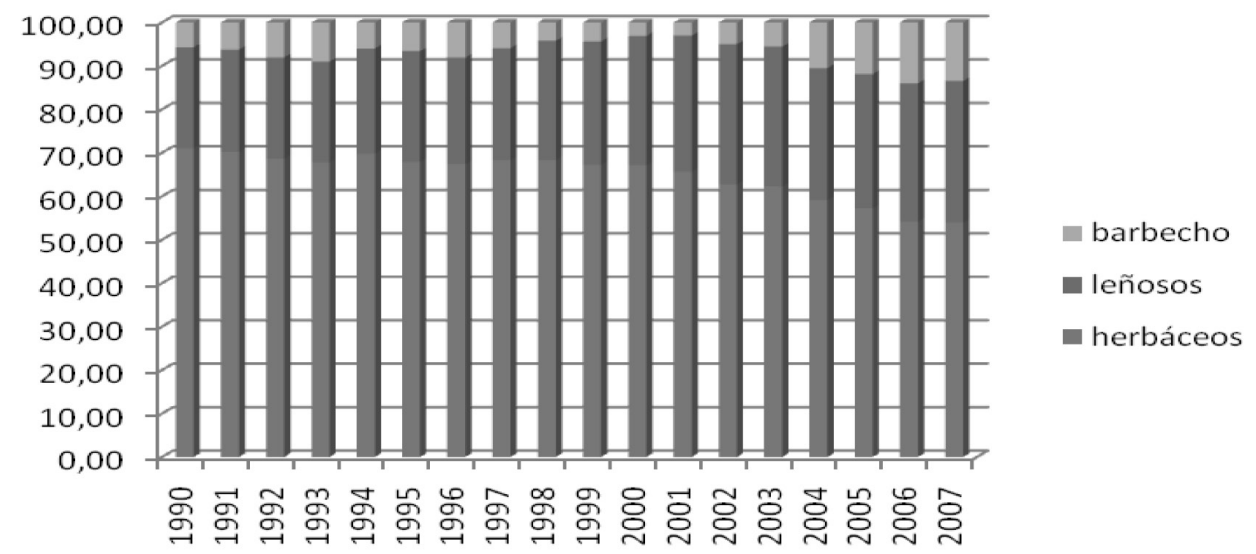

Figura 4. Evolución de los principales grupos de aprovechamientos en regadío (19902007), en porcentaje.

Fuente: MAPA, 1991 y MARM, 2009. Elaboración propia.

La dinámica de las tierras de cultivo adquiere una mayor relevancia territorial y socioeconómica al analizar la evolución registrada por los principales aprovechamientos en los últimos diez años (tabla 2). Esta evolución debe, no obstante, considerar como elemento de partida, la situación de preeminencia que los cultivos herbáceos tienen tanto en el secano como en el regadío español: ocupan el 55\% de las 3.689.456 ha regadas. Esta situación de privilegio de los herbáceos encubre realidades diversas, ya que junto a aprovechamientos extensivos (cereales y cultivos industriales) encontramos explotaciones altamente intensivas como son las flores y algunas variedades hortícolas cultivadas en invernaderos. Igualmente, ha de tenerse en cuenta que hortícolas, cítricos y prunus ocupan 473.715 ha., el 13,8\% del total, a seis puntos porcentuales por debajo, por ejemplo, de la superficie regada por el olivar, pero aglutinan alrededor del $80 \%$ del total de las exportaciones de la producción vegetal. 
Tabla 1

DISTRIBUCIÓN REGIONAL DE LOS CULTIVOS EN REGADÍO EN HECTÁREAS (2008)

\begin{tabular}{|l|r|r|r|r|r|r|r|r|}
\hline & $\begin{array}{c}\text { Cereales } \\
\text { grano }\end{array}$ & $\begin{array}{c}\text { Cultivos } \\
\text { industriales }\end{array}$ & Forrajeras & $\begin{array}{c}\text { Hortalizas } \\
\text { y flores }\end{array}$ & Cítricos & Frutales & Viñedo & Olivar \\
\hline Navarra & 37.142 & 278 & 6.734 & 7.852 & 0 & 2.680 & 12.979 & 2.934 \\
Rioja & 9.712 & 656 & 1.050 & 2.386 & 0 & 4.898 & 19.988 & 1.390 \\
Aragón & $\mathbf{2 0 0 . 1 4 9}$ & 3.335 & $\mathbf{8 5 . 6 0 9}$ & 4.308 & 0 & $\mathbf{4 4 . 5 3 0}$ & 11.222 & 9.335 \\
Cataluña & 89.054 & 2.859 & 31.038 & 7.787 & 12.447 & 12.447 & 7.355 & 18.501 \\
C. León & $\mathbf{2 1 0 . 2 6 1}$ & $\mathbf{5 5 . 1 0 2}$ & $\mathbf{4 9 . 1 1 9}$ & 9.108 & 0 & 2.008 & 14.721 & 1.031 \\
C.-La Mancha & 128.247 & 10.034 & 19.159 & $\mathbf{3 9 . 4 2 2}$ & 0 & 5.261 & $\mathbf{2 1 2 . 4 6 2}$ & 44.143 \\
C. Valenciana & 18.047 & 15 & 1.969 & 14.000 & $\mathbf{1 8 7 . 3 2 0}$ & $\mathbf{3 0 . 1 9 4}$ & 24.158 & 24.158 \\
Murcia & 4.124 & 347 & 551 & $\mathbf{4 8 . 0 3 2}$ & 41.266 & $\mathbf{3 8 . 5 2 3}$ & 10.401 & 8.219 \\
Extremadura & 102.330 & 11.422 & 26.400 & 21.305 & 317 & 12.913 & 16.110 & 30.549 \\
Andalucía & 88.223 & $\mathbf{8 7 . 0 6 7}$ & 11.517 & $\mathbf{5 0 . 4 7 9}$ & $\mathbf{7 9 . 9 0 2}$ & $\mathbf{3 7 . 2 1 8}$ & 3.998 & $\mathbf{5 2 6 . 1 3 9}$ \\
Otras & 10.722 & 2.000 & 9.000 & 9.995 & 1.753 & $\mathbf{5 7 . 0 0 9}$ & 6.724 & 200 \\
\hline Total & $\mathbf{8 9 8 . 0 1 0}$ & $\mathbf{1 7 3 . 8 3 2}$ & $\mathbf{2 4 2 . 4 2 4}$ & $\mathbf{2 1 4 . 6 7 4}$ & $\mathbf{3 2 3 . 0 0 4}$ & $\mathbf{2 4 7 . 6 8 0}$ & $\mathbf{3 4 0 . 1 1 8}$ & $\mathbf{6 6 6 . 6 0 0}$ \\
\hline
\end{tabular}

Fuente: MARM, 2009. Elaboración propia.

Tabla 2

EVOLUCIÓN DE LOS PRINCIPALES APROVECHAMIENTOS EN REGADÍO (1996-2007)

\begin{tabular}{|l|rr|r|r|rr|}
\hline & \multicolumn{2}{|c|}{$\mathbf{1 9 9 6}$} & \multicolumn{2}{c|}{$\mathbf{2 0 0 7}$} & \multicolumn{2}{c|}{ Evolución (2007-1996) } \\
\cline { 2 - 7 } & $\begin{array}{c}\text { Sup } \\
\text { regada } \\
\text { (ha) }\end{array}$ & $\begin{array}{r}\text { \% sobre } \\
\text { sup total }\end{array}$ & $\begin{array}{c}\text { Sup } \\
\text { regada } \\
\text { (ha) }\end{array}$ & $\begin{array}{c}\text { \% sobre } \\
\text { sup total }\end{array}$ & $\begin{array}{c}\text { Sup. } \\
\text { regada (ha) }\end{array}$ & $\begin{array}{c}\text { Incremento } \\
\text { \% sobre sup } \\
\text { regada }\end{array}$ \\
\hline Total* $^{\mid}$ & $\mathbf{3 . 4 2 6 . 9 0 0}$ & $\mathbf{1 7 , 9 1}$ & $\mathbf{3 . 6 8 9 . 4 0 2}$ & $\mathbf{2 1 , 2 1}$ & $\mathbf{2 6 2 . 5 0 0}$ & $\mathbf{3 . 3 1}$ \\
\hline Trigo & 206.015 & 10,24 & 223.305 & 12,38 & $\mathbf{1 7 . 2 9 0}$ & $\mathbf{2 , 1 5}$ \\
Maíz & 364.389 & 82,87 & 336.188 & 93,13 & $\mathbf{- 2 8 . 2 0 1}$ & $\mathbf{1 0 , 2 6}$ \\
Hortalizas & 356.678 & 89,45 & 356.025 & 93,77 & $\mathbf{- 6 5 3}$ & $\mathbf{4 , 3 2}$ \\
Cítricos & 275.671 & 100,00 & 315.580 & 100,00 & $\mathbf{3 9 . 9 0 9}$ & $\mathbf{0 , 0 0}$ \\
Olivar & 173.621 & 8,18 & 361.967 & 15,74 & $\mathbf{1 8 8 . 3 5 5}$ & $\mathbf{7 , 7 7}$ \\
Viñedo $^{2}$ & 62.863 & 5,59 & 190.955 & 17,21 & $\mathbf{1 2 8 . 0 9 6}$ & $\mathbf{1 1 , 6 2}$ \\
Arrozal $^{2}$ & 106.531 & 100,00 & 105.072 & 100,00 & $\mathbf{- 1 . 4 5 9}$ & $\mathbf{0 , 0 0}$ \\
\hline
\end{tabular}

* Se incluye la superficie en barbecho; ${ }^{1}$ : olivar almazara; ${ }^{2}$ : viñedo para vinificación: Fuente: MAPA, 1999 y MARM, 2009. Elaboración propia. 
Los cereales, en su conjunto, han registrado un incremento en el periodo objeto de análisis (1996-2007) cifrado en unas 135.000 hectáreas, que corresponde en un porcentaje muy elevado al aumento de la superficie ocupada por la cebada, frente a la estabilidad de otros aprovechamientos como el trigo o la reducción de cereales típicamente de regadío como es el caso del maíz. Son las comunidades autónomas de Castilla y León $(33,57 \%)$, Aragón (19,92\%), Extremadura (15,77\%) y Castilla-La Mancha $(9,10 \%)$, las que concentran un porcentaje muy elevado de ese aprovechamiento (maíz) a partir de la explotación de acuíferos y de aguas superficiales derivadas de los grandes ríos ibéricos. En el trigo, son las llanuras sedimentarias y páramos de la submeseta norte, las campiñas andaluzas y los llanos de la depresión del Ebro, las áreas que concentran la mayor parte del terrazgo dedicado a este aprovechamiento. El aumento de las dimensiones de las unidades de explotación, su elevada mecanización y el reducido empleo de asalariados son factores que contribuyen al mantenimiento de las superficies cultivadas desde finales de los ochenta: los leves incrementos o decrecimientos, compensan las pérdidas y ganancias de superficie. Excepción a esta tendencia moderada es la provincia de Zaragoza que ha visto ampliada notablemente la superficie destinada al trigo en los últimos veinte años. En el proceso inverso aparece la campiña sevillana, donde terrazgos tradicionalmente destinados al cultivo del trigo han sido destinados a otros aprovechamientos, entre los que destaca el olivar.

Tabla 3

EVOLUCIÓN DE LAS SUPERFICIES HORTÍCOLAS (1996-2007)

\begin{tabular}{|c|c|c|c|c|c|c|}
\hline & \multicolumn{2}{|c|}{ Aire libre } & \multicolumn{2}{|c|}{ Protegido } & \multicolumn{2}{|c|}{ Evolución 2007-1996 } \\
\hline & $\begin{array}{l}1996 \\
\text { (ha) }\end{array}$ & $\begin{array}{c}2007 \\
\text { (ha) }\end{array}$ & $\begin{array}{l}1996 \\
\text { (ha) }\end{array}$ & $\begin{array}{l}2007 \\
\text { (ha) }\end{array}$ & $\begin{array}{l}\text { Aire libre } \\
\text { (ha) }\end{array}$ & $\begin{array}{l}\text { Protegido } \\
\text { (ha) }\end{array}$ \\
\hline Galicia & 6.548 & 5.728 & 533 & 2.117 & -820 & 1.584 \\
\hline Asturias & 0 & 142 & 84 & 109 & 142 & 25 \\
\hline Cantabria & 38 & 0 & 35 & 0 & -38 & -35 \\
\hline País Vasco & 1.076 & 1.345 & 192 & 262 & 269 & 70 \\
\hline Navarra & 13.956 & 17.371 & 307 & 271 & 3.415 & -36 \\
\hline Rioja & 11.412 & 6.166 & 240 & 153 & -5.246 & -87 \\
\hline Aragón & 13.103 & 8.977 & 31 & 33 & -4.126 & 2 \\
\hline Cataluña & 18.329 & 12.948 & 1.324 & 539 & -5.381 & -785 \\
\hline Baleares & 5.230 & 2.095 & 1.053 & 226 & -3.135 & -827 \\
\hline C. León & 15.481 & 14.704 & 147 & 122 & -777 & -25 \\
\hline Madrid & 6.444 & 1.645 & 0 & 171 & -4.799 & 171 \\
\hline C. Mancha & 44.122 & 47.578 & 1.691 & 280 & 3.456 & -1.411 \\
\hline C. Valenciana & 25.834 & 22.275 & 2.677 & 2207 & -3.559 & -470 \\
\hline Murcia & 33.565 & 42.653 & 4.565 & 5561 & 9.088 & 996 \\
\hline Extremadura & 28.199 & 26.801 & 3.400 & 3938 & -1.398 & 538 \\
\hline Andalucía & 59.073 & 67.790 & 50.116 & 55.386 & 8.717 & 5.270 \\
\hline Canarias & 3.793 & 3.504 & 3.940 & 2928 & -289 & -1.012 \\
\hline Total & 286.203 & 281.722 & 70.335 & 74.303 & -4.621 & 3.968 \\
\hline
\end{tabular}

Fuente: MAPA, 1999 y MARM, 2008. Elaboración propia. 
Un comentario particular reviste el cultivo del arroz, dados los elevados módulos de consumo de agua (entre 10.000 y $14.000 \mathrm{~m}^{3} / \mathrm{ha}$ ). La evolución registrada desde 1999 se caracteriza por un mantenimiento de las superficies de manera global: las 106.531 ascienden a 118.713 en 2009. Esa tendencia ligeramente alcista, que se acentúa si comparamos estas superficies con las de mediados de los ochenta, cuando ésta se situaba en torno a las 75.000 ha, encubre dinámicas territoriales contrastadas. Frente al mantenimiento de las áreas cultivadas, cuando no disminución en la Comunidad Valenciana y Cataluña ${ }^{2}$, Andalucía, Extremadura y Aragón han registrado incrementos significativos en sus superficies. La primera ha visto ampliado el arrozal en unas 10.000 hectáreas entre 1996 y 2009; concentrando alrededor del $33 \%$ del total de la superficie nacional. Aumentos en torno a las 8.000 y 4.000 ha se registran en Extremadura y Aragón. Estas diferencias se asocian también a funciones diversas. Frente a los tradicionales espacios de arrozal (delta del Ebro, Albufera de Valencia, Marismas del Guadalquivir), donde la función productiva se ve fortalecida por las externalidades que genera (mantenimiento de espacios de gran valor ecológico), los nuevos arrozales, creados en antiguos secanos, carecen de esta última. Ejemplo de ello son las nuevas plantaciones en Monegros, las Bárdenas Reales o las vegas pacenses.

Las hortalizas en su conjunto se caracterizan por un mantenimiento de las superficies cultivadas: entre 1996 y 2007, ésta ha decrecido en unas 600 hectáreas; cifras que encubren una realidad dual, frente a la reducción de las superficies al aire libre, se produce un incremento de las cultivadas en invernadero (tabla 3). Es la provincia de Almería, la que sigue concentrando un porcentaje muy elevado de la superficie bajo plástico $(74,4 \%$ del total en 2007). La intensificación en las prácticas de cultivo es la opción elegida en provincias como Alicante, Murcia o la propia Almería para competir con la llegada de productos procedentes del norte de África, la escasez de recursos hídricos o la competencia que sobre suelo y agua ejercen los usos urbano-residenciales. En las superficies al aire libre, junto a las provincias de Almería, Murcia y Alicante, adquieren importancia las plantaciones en Castilla-La Mancha. Este último proceso se vincula al traslado de las áreas de cultivo hacia tierras de transición, desde el punto de vista climático, que permiten su siembra desde finales del invierno hasta bien entrado el verano (municipios del Altiplano de Jumilla-Yecla y del Alto Vinalopó) o hacia comarcas más interiores (Sureste de Albacete o Ciudad Real, por ejemplo) con caudales abundantes.

Frente a la tendencia al mantenimiento e, incluso, retroceso que registran los herbáceos, la dinámica registrada por los leñosos es claramente alcista (figura 4): han pasado de ocupar el 23\% de las tierras cultivas en 1996 al 33\% en 2007. Esta dinámica encubre situaciones claramente diferenciadas Son aprovechamientos tradicionalmente de secano como el olivar y el viñedo, los que registran los incrementos más espectaculares (tabla 2). El olivar, según las cifras oficiales ha triplicado la superficie de regadío en los últimos diez años y el viñedo casi las ha cuadruplicado. Éstas, si bien, no recogen la totalidad de ese proceso de transformación, como pone de manifiesto la comparación entre datos estadísticos y los trabajos de campo (véase lo que se indica en el epígrafe Introducción, al respecto), evidencian esa intensa dinámica.

2 La superficie ocupada por el arrozal en 2009 en la Comunidad Valenciana ascendía a 15.213 hectáreas frente a las 16.296 de 1996. En Cataluña, la dinámica es similar: las 21.595 ha. de 1996, se han visto reducidas en 462 en 2009. 


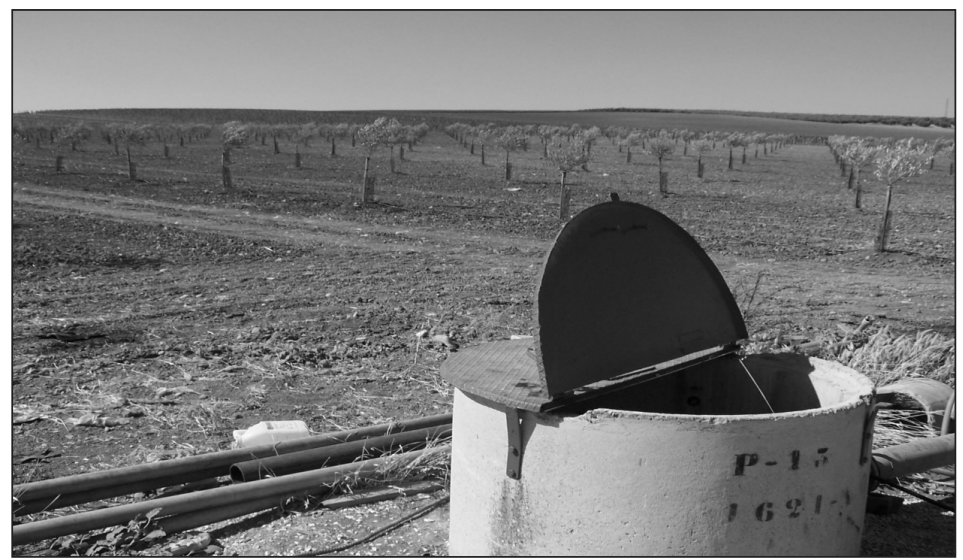

Figura 5. Plantación de olivar con riego a presión en el área regable del Genil-Cabra.

El olivar ha pasado de unas 199.000 ha en 1996 a unas 645.526 en 2009, según cifras oficiales; incremento que corresponde, en torno a un $80 \%$, a la aceituna para almazara. Este cultivo se caracteriza por una fuerte concentración espacial en Andalucía, concretamente en las campiñas béticas (Jaén, Córdoba, Sevilla y Granada) y Extremadura (Badajoz). La provincia de Jaén con unas 81.585 ha., el 43,3\% de las nuevas roturaciones en regadío, constituye el ejemplo más importante de la difusión de sistemas de regadío, generalmente mediante riego por goteo, en antiguos secanos, pero también en nuevas plantaciones (figura 5). Esta dinámica alcista se vincula a un doble proceso. Por un lado, al incremento de la productividad al aminorarse la vecería gracias a la difusión de sistemas de regadío. Por otro, a su mayor rentabilidad; resultado del aumento de las subvenciones comunitarias a partir de la década de los noventa como consecuencia de la equiparación paulatina de las subvenciones españolas a las del resto de la Unión Europea y del precio pagado por kilo de aceite gracias a la introducción de nuevas técnicas de elaboración, que mejoran notablemente la calidad final de este producto. En ese proceso expansivo, se han puesto en cultivo áreas poco favorables, desde el punto de vista climático. Representativos resultan los daños en plantaciones nuevas debido a las heladas del invierno de 2009-2010 en algunas comarcas de Castilla-La Mancha.

El viñedo para vinificación ha registrado, también, una evolución claramente alcista: las superficies regadas en 2009 (314.079 hectáreas) se han multiplicado casi por cuatro con respecto a las de 1996 (81.736 ha); incremento que corresponde en su totalidad al viñedo de vinificación frente a la uva de mesa caracterizada por una fuerte atonía. Es la Comunidad de Castilla-La Mancha, con 76.964 hectáreas, la que concentra el mayor aumento superficial, ya que aglutina el 55\% de las nuevas superficies en regadío. Esta dinámica positiva contrasta con la disminución de las superficies cultivadas en secano, que se han reducido en unas 140.000 ha. Este comportamiento dual es resultado en gran medida de la intensificación de los sistemas de cultivo (figura 6) mediante la difusión de regadío (generalmente por goteo), la introducción de técnicas de cultivo más intensivas (espaldera) y nuevas variedades y el abandono de viñedos marginales. La mayor producción de estos viñedos (unos $9.000 \mathrm{~kg} / \mathrm{ha}$ ) frente a los tradicionales en secano (unos $3.000 \mathrm{~kg} / \mathrm{ha}$ ) se ha traducido en un importante incremento de la producción y la aparición de importantes volúmenes de excedentes, que tratan de ser aminorados mediante subvenciones orientadas a favorecer su arranque. De los 476.410.960 $\square$ abonados por el FEGA en el ejercicio 2009 
a la OCM del viñedo, el 48\% correspondían a primas para su arranque (FEGA, 2010). Paradójicamente, se eliminan viñedos que tenían una producción media anual de 840.000 Tm de uva en cultivo pluvial y marco de unas 1.500 cepas/hectárea, frente a la puesta en cultivo de unas 75.000 hectáreas en regadío con goteo y espaldera, de más de 3.000 cepas/ hectárea, que pueden producir 1.800.000 Tm de uva para vinificación (Morales, 2001). Este proceso evidencia las contradicciones entre la PAC y las ayudas de las comunidades autónomas al cultivo del viñedo con goteo, que puede duplicar en una menor superficie de cultivo, el volumen de vino obtenido. Se está favoreciendo, por tanto, el aumento de producción, frente a lo propuesto en las ayudas al arranque, que era el de su reducción. El problema de los excedentes de vino no se soluciona, sino que se acrecienta. Consiguientemente, junto a las ayudas para el abandono de superficies, otra de las subvenciones se orienta a la destilación de vinos y alcohol, que concentraron el 29\% de la ayudas del FEGA a este cultivo. Y, además, consumiendo en abundancia agua y energía y generando menores repercusiones socioeconómicas en las comarcas que en décadas pasadas, dado el alto grado de mecanización en poda y recolección.

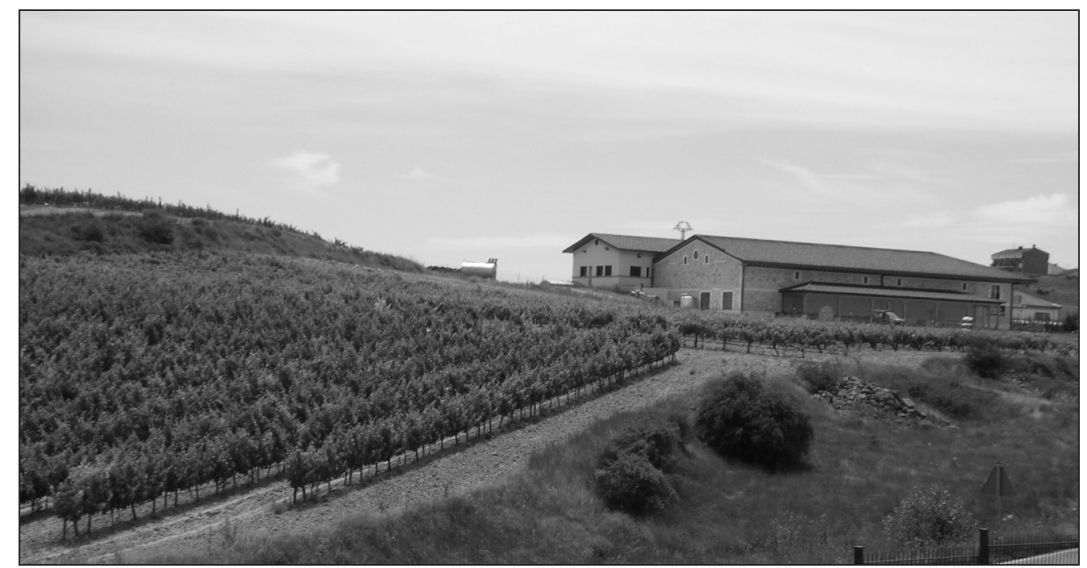

FiguRa 6. Nuevas plantaciones de viñedo en espaldera y riego por goteo en la D.O. Ribera del Duero.

Esta dinámica contrasta con una evolución más contenida de los cítricos y de algunos frutales, que constituían los tradicionales aprovechamientos de los leñosos en regadío. Los cítricos han registrado un incremento de unas 36.000 hectáreas; cifra que encubre realidades diversas: el aumento en la Comunidad de Andalucía (32.000 hectáreas) y, en menor medida, de Cataluña y Murcia, contrasta con la reducción en la Valenciana (figura 7). El incremento de superficies en Andalucía se relaciona con la introducción de variedades destinadas a la fabricación de zumos, básicamente. En Comunidades, como la Valenciana, además de la reducción de superficies, se ha producido un significativo ajuste varietal. Éste se ha dirigido a sustituir variedades de naranjos por otras de mandarinos, dada la menor rentabilidad económica de aquéllos, al registrar cada vez más una mayor competencia de producciones en fresco y en zumos procedentes de Marruecos, Sudáfrica o Brasil. Los cambios varietales acaecidos en los mandarinos (frutos más precoces, sin semillas, de fácil pelado, con mejores condiciones organolépticas y con posibilidad de propiciar ritmos de 
recolección escalonados durante la campaña de comercialización) han permitido su adaptación a los gustos de los consumidores, por lo que algunas de sus variedades (clementinas, oroval, clemenules o marisol) son muy competitivas en los mercados de la Unión Europea, Canadá o Estados Unidos. A pesar de estas transformaciones, un porcentaje importante de estos cítricos presenta importantes problemas de rentabilidad, que se han plasmado en el significativo abandono de superficies en los últimos años, alrededor de unas 7.000 hectáreas entre 2007 y 2009. Pérdida que prácticamente en su totalidad se concentra en la Comunidad Valenciana. La evolución de las superficies ocupadas por el limón es un ejemplo paradigmático, de constituir un aprovechamiento mayoritario en las comarcas meridionales de Alicante y Murcia, la caída drástica en los precios percibidos por los agricultores se ha plasmado en una reducción de la superficie ocupada y, paralelamente, su sustitución por otras variedades de cítricos (naranjas tardías y mandarinas): la superficie ha pasado de ocupar alrededor del 50 al 40\% entre 1998 y 2007, en aquellas comarcas. La variabilidad de los precios se relaciona con factores diversos entre los que debe citarse la competencia ejercida por terceros países, que varía dependiendo de las condiciones climáticas invernales en algunos de ellos y la aplicación de aranceles a la importación.

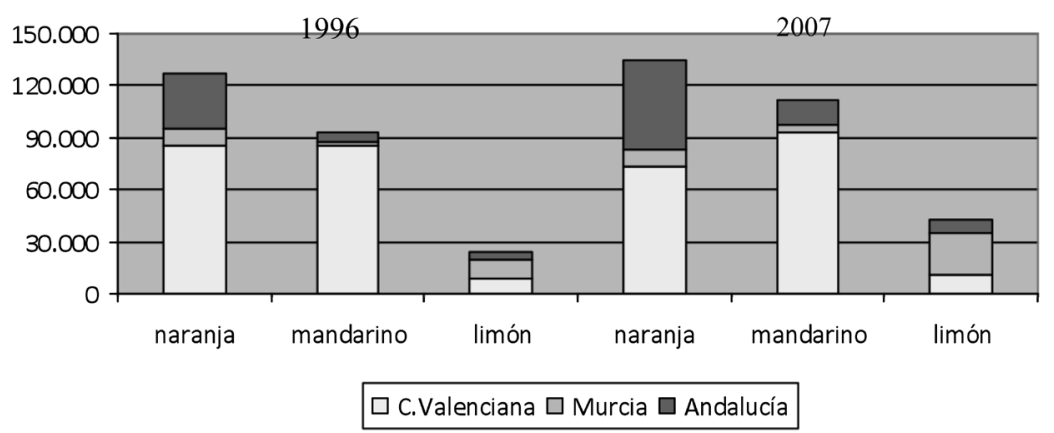

Figura 7. Evolución de las superficies de cítricos, en ha., según variedades (1996-2007). Fuente: MAPA, 1999 y MARM, 2008. Elaboración propia.

La trascendencia de las ayudas de la PAC en el mantenimiento de algunos cultivos (cereales) y la expansión de otros (olivar) así como la necesidad de aplicar políticas orientadas a la aminoración de los excedentes (viñedo) queda evidenciada al analizar los pagos realizados por el FEGA. Por Pago Único en el año 2009, las regiones con mayor volumen de subvenciones se localizan en Andalucía, Castilla-León y Castilla-La Mancha, que concentran el $67 \%$ del total de las ayudas. Esta centralización se vincula con su entidad superficial, pero también con la existencia de aprovechamientos que aúnan porcentajes significativos de esas ayudas (herbáceos, olivar y viñedo). El análisis de las ayudas por cultivos (tabla 4) pone de manifiesto los contrastes entre los regadíos extensivos en los que predominan las ayudas a la superficie y los regadíos más intensivos en los que las subvenciones se han aplicado a la transformación de cítricos y otras frutas. Las ayudas a la producción también son fundamentales para entender la fuerte expansión que ha protagonizado el olivar. Idéntica trascendencia revisten las intervenciones comunitarias en el sector vitivinícola, mediante la compra de alcohol de las destilaciones obligatorias, ayudas al almacenamiento privado de vinos y mostos o restituciones a la exportación. 
Tabla 4

TRANSFERENCIAS EN口DEL FEAGA POR SECTORES (EJERCICIO 2009) EN ESPAÑA

\begin{tabular}{|c|c|c|}
\hline APROVECHAMIENTO & \multicolumn{2}{|c|}{ TOTAL (en miles de $\square$ ) } \\
\hline $\begin{array}{l}\text { Cultivos herbáceos (total) } \\
\text { o Ayuda por superficie }\end{array}$ & $354.972,83$ & $416.315,88$ \\
\hline $\begin{array}{l}\text { Arroz (total) } \\
\qquad \text { o Ayuda por superficie }\end{array}$ & $42.762,66$ & $42.762,66$ \\
\hline $\begin{array}{l}\text { Leguminosas grano (total) } \\
\text { o Ayuda por superficie }\end{array}$ & 218,36 & 218,36 \\
\hline $\begin{array}{l}\text { Cultivos energéticos (total) } \\
\text { o Ayuda por superficie }\end{array}$ & 387,74 & 387,74 \\
\hline $\begin{array}{l}\text { Aceite de oliva (total) } \\
\qquad \text { o Ayuda al olivar }\end{array}$ & $95.189,36$ & $96.143,99$ \\
\hline $\begin{array}{l}\text { Frutas y hortalizas (total) } \\
\qquad \begin{array}{l}\text { o Ayuda por superficie a los frutos de cáscara } \\
\text { o Ayuda transformación de cítricos }\end{array}\end{array}$ & $\begin{array}{l}66.943,43 \\
10.566,70\end{array}$ & $351.518,49$ \\
\hline $\begin{array}{l}\text { Algodón (total) } \\
\text { o Ayuda por superficie }\end{array}$ & $51.871,98$ & $64.666,74$ \\
\hline $\begin{array}{l}\text { Tabaco (total) } \\
\text { o Ayuda a la producción }\end{array}$ & $63.754,80$ & $65.991,96$ \\
\hline $\begin{array}{l}\text { Forrajes (total) } \\
\qquad \text { o Ayuda a la producción de forrajes desecados }\end{array}$ & $55.434,28$ & $55.434,28$ \\
\hline TOTAL ejercicio & & $6.068 .452,14$ \\
\hline
\end{tabular}

FEGA, 2010. Elaboracion propia.

\section{Las superficies regadas según el origen de las aguas y la tipología de riego: incre- mento de los caudales subterráneos y expansión del riego localizado}

Las superficies regadas españolas han registrado un significativo incremento desde mediados del siglo XX. Esta expansión ha sido considerada como una estrategia de desarrollo agrario con fondos públicos. Las grandes zonas regables de iniciativa pública, en sus diferentes versiones, desempeñaron un papel de «reforma agraria». Numerosas actuaciones (Monegros, Bárdenas Reales, etc.) han permitido ampliar las zonas regadas en los valles de los principales cursos fluviales españoles. La utilización de caudales superficiales se completa con los subterráneos (La Mancha y Andalucía). El empleo de potentes bombas, desde mediados de los sesenta que extraen las aguas de los acuíferos, ha permitido la expansión de nuevas áreas regadas mediante las transformaciones en regadío de secanos, eriales o monte bajo. El uso de estos caudales, considerados estratégicos en algunas comarcas, ha generado notables transformaciones paisajísticas en el levante español y en las provincias castellano-manchegas, pero también ha creado importantes procesos de degradación ambiental, entre los que destacan su sobreexplotación o la notable reducción de las zonas húmedas. La escasez de recursos hídricos en algunas regiones españolas explica la utiliza- 
ción de fuentes no convencionales de suministro (aguas depuradas y desaladas). Entidades de riego del Medio Vinalopó como la CR de Monforte del Cid junto a otras del Campo de Alicante (CR Alicante Norte) fueron pioneras en España en la utilización de las aguas procedentes de EDARs para el riego de cultivos comerciales a finales de los años ochenta (Rico y Olcina, 1996). Su uso se orientaba a incrementar unos recursos insuficientes (los subterráneos) y cuyo encarecimiento progresivo causaba una pérdida de rentabilidad de numerosos cultivos.

El análisis de la evolución registrada por los consumos hídricos de los regadíos españoles en la última década pone de manifiesto el incremento de éstos como consecuencia de la expansión de las áreas regadas (figura 8). Una segunda conclusión, no menos interesante, es el hecho de que a pesar del predominio de las aguas superficiales, éstas se caracterizan por una ligera tendencia a la disminución frente al significativo incremento de las subterráneas. Ello permite aventurar que la creación y/o consolidación de áreas regadas en algunos territorios se ha producido como consecuencia de la sobreexplotación de acuíferos; lo que contribuye a acentuar los problemas medioambientales de esos territorios. La tercera, es la puntual utilización de recursos no convencionales. Esta dinámica a escala nacional encubre, sin embargo, notables diferencias a nivel regional. Son aquellas comunidades con menores recursos hídricos superficiales (Canarias, Baleares y Valencia) dada su indigencia pluviométrica, que soportan algunas de sus comarcas, donde los recursos subterráneos y no convencionales tienen una mayor presencia.

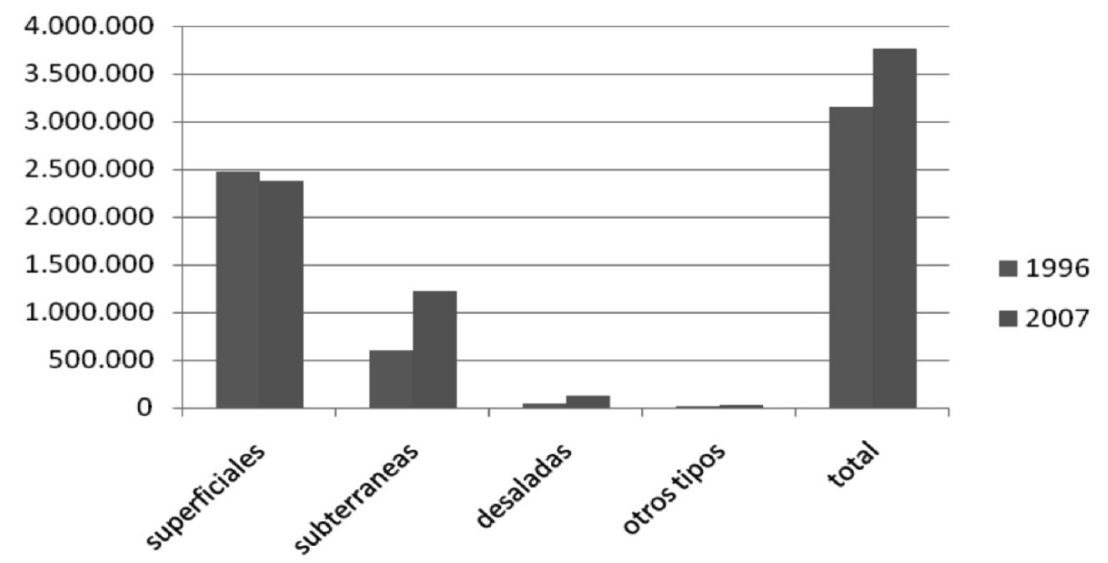

Figura 8. Evolución de la procedencia de las aguas en los regadíos españoles (miles de metros cúbicos): 1996-2007.

Fuente: INE. Elaboración propia.

Mayor interés territorial y paisajístico reviste el análisis de las tipologías de riego. La dinámica de la última década (figura 9) pone de manifiesto una mayor intensidad de cambio, que en periodos precedentes. La disminución de las superficies regadas por gravedad es paralela al incremento de las asociadas a riego localizado y mediante aspersión. Esta evolución se relaciona a diversos procesos. En primer lugar, la modernización de regadíos se vincula a la sustitución de los sistemas de riego por inundación por otros con manejo de agua entubada, dada la mayor efectividad de éstos y las menores dotaciones 
hídricas que requieren. Ello, si bien ha permitido, en algunos casos, la expansión de los regadíos, está generando, junto a otros factores, la desaparición de los regadíos tradicionales; entendidos éstos, además de su función productiva, como paisajes con elevada biodiversidad y valor cultural. En segundo lugar, los menores costes económicos que comportan las transformaciones en regadío de antiguos secanos al no ser necesario la adecuación de los terrazgos. Y, por último, su difusión unida a la conversión en regadíos de cultivos tradicionalmente pluviales. La expansión de viñedos y olivares va indisolublemente asociada al riego por goteo.

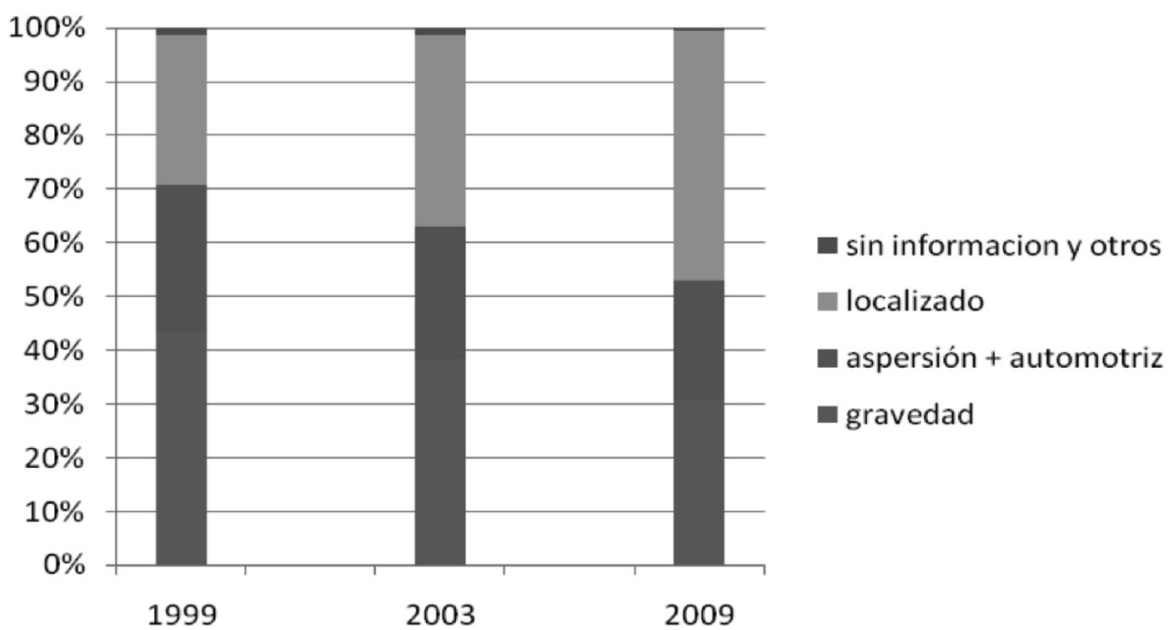

FIGURA 9. Evolución de la superficie regada, en porcentaje, según tipología de riego (1999-2009) Fuente: MAPA, 1999 y MARM, 2009. Elaboración propia.

El análisis a escala regional de las tres principales tipologías de riego permite poner de manifiesto algunas de las dinámicas que caracterizan a los regadíos españoles en la última década.

Los regadíos por gravedad disminuyen en todas las comunidades, sobre todo, por la reducción de los riegos tradicionales de las huertas mediterráneas (Plana de Castellón, Horta de Valencia, Vega Baja en Alicante y Huerta de Murcia). A los procesos de modernización, se unen los conflictos que los usos agrarios mantienen con los urbano-turísticos en el acceso a los recursos suelo y agua. La ubicación de éstos en los fondos de valle y en las llanuras litorales determina que la expansión urbana y los procesos de rururbanización se realicen sobre ellos. Contrariamente, se observa un ligero incremento superficial allí donde se expande el cultivo del arrozal, como acontece en las Bárdenas Reales, Monegros, Vegas pacenses del Guadiana y marismas del Guadalquivir. Las iniciativas orientadas a la modernización de regadíos mediante la sustitución del riego a manta por aspersión y goteo es una dinámica que desde finales de los noventa del pasado siglo ha sido auspiciada desde las diferentes administraciones en aquellas regiones con recursos hídricos insuficientes. El objetivo final de todas ellas es reducir las dotaciones por hectárea, que, tradicionalmente, eran elevadas. 
Los regadíos mediante sistemas de aspersión fija y automotriz se caracterizan por presentar una marcada localización territorial: el $85 \%$ se concentra en las comunidades autónomas de Castilla-La Mancha, Castilla y León y, en menor medida, Andalucía y Aragón. Ello viene determinado por los cultivos a los que se asocia, cereales y cultivos industriales. La tendencia en la última década (1999-2009) ha sido la reducción de superficies, especialmente significativa en Castilla-La Mancha y Andalucía, frente a procesos más matizados en Castilla y León. La expansión de viñedos y olivar sobre terrazgos cerealícolas es una de las razones que explica la reducción de esta tipología de riego. La excepción a esta tendencia es Aragón, que ha visto incrementada su superficie regada mediante sistemas de aspersión en unas 33.816 hectáreas. La creación de nuevos regadíos dedicados a cultivos herbáceos extensivos explica su aumento.

Las superficies con riego localizado son los que registran los mayores incrementos: de unas 914.410 hectáreas en 1999 se ha pasado a 1.591.615 (MARM, 2009). Se puede afirmar que, gran parte de la expansión de los regadíos españoles, se asocia con esta técnica de riego; pero también con la conversión de espacios regados mediante el riego a manta a sistemas localizados a través de las iniciativas de mejora y modernización de regadíos tradicionales. En la década de los años setenta, con la implantación de apreciables superficies de invernaderos en el sureste peninsular y, especialmente, en el Campo de Dalias, se hizo necesario controlar los flujos de agua que directamente debían aplicarse sobre el aparato radicular de las plantas, por lo que se utilizaron tecnologías de circuitos hidráulicos que aportasen los volúmenes necesarios del líquido elemento y que previamente hubieran sido enriquecidos con nutrientes. Así, se procedió a implantar la tecnología de riego localizado, también llamada de goteo, que ya se utilizaba en Holanda, Israel, USA e Italia, y que se había revelado de gran utilidad. Al mismo tiempo, el sistema de riego localizado se mostró como gran economizador de volúmenes de agua en unos territorios que contaban con unas disponibilidades reducidas, por debajo de las demandas, por lo que se vio la utilidad de aplicarlos a áreas con tradición de riego. En consecuencia, en las décadas de finales del siglo XX, se aplicaron a grandes superficies de cultivos citrícolas, frutales y hortalizas de ciclo corto al aire libre. Son las huertas valencianas, murcianas y andaluzas las que experimentaron las grandes transformaciones en aquellos años. En 1997, el riego localizado ascendía a 750.00 ha, un 22,72\% del total (Morales, 1999). En la última década del siglo XX y la primera del actual, el incremento de superficies de riego por goteo ha seguido una trayectoria ascendente; pero ahora, los cultivos a los que más se les aplica son el olivar y el viñedo de vinificación. Estos dos aprovechamientos han visto aumentar sus superficies notablemente en Andalucía y Castilla-La Mancha. Ambas suman alrededor del 65\% de las 677.205 nuevas hectáreas con riego con goteo entre 1999 y 2009 (figura 10). Aquélla es la comunidad autónoma que concentra el porcentaje de superficie más elevado de esta tipología de riego, pero también la que ha registrado el mayor incremento. En la última década, casi ha duplicado esta superficie, al pasar de 412.306 hectáreas en 1999 a 716.837 en 2009. Dos son los factores que justifican la expansión del proceso. Por un lado, la importancia que este sistema de riego presenta en los cultivos hortícolas intensivos y, por otro, su difusión asociado a un cultivo tradicionalmente de secano como es el olivar. En la actualidad, la superficie afectada por el riego localizado a escala nacional representa el $50 \%$ del total. Esta trayectoria parece que todavía no ha tocado techo y que reemplazará al viejo sistema de inundación de las parcelas, en casi todos los cultivos arbóreos y en aquellos hortícolas de vocación exportadora; mientas que se mantendrán el de aspersión en cereales e industriales y los riesgos a manta, perdurarán en las huertas tradicionales y en el arrozal, básicamente. 


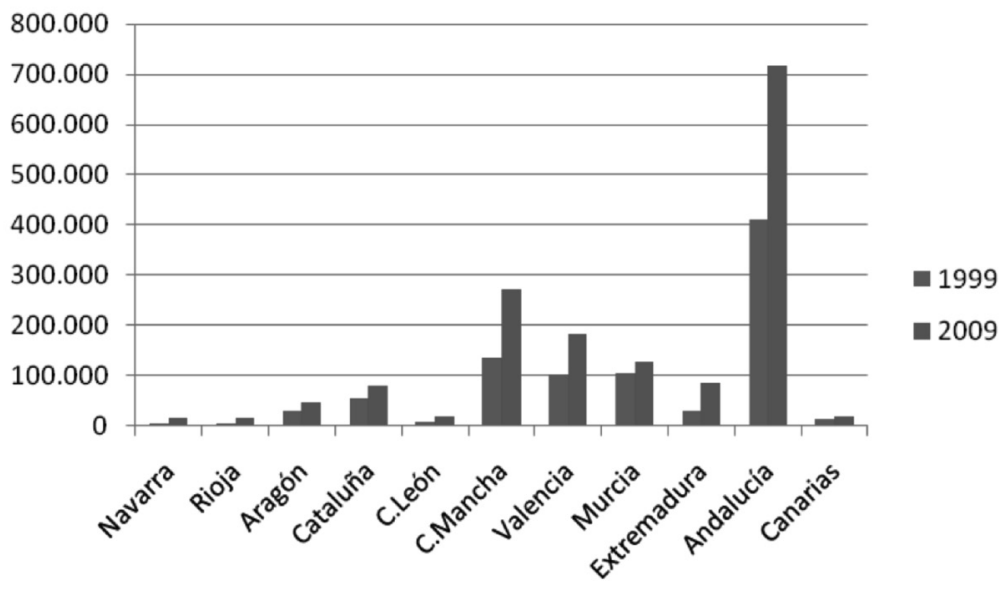

FIGURA 10. Evolución de las superficies con riego localizado (1999-2009), en hectáreas. Fuente: MAPA, 2000 y MARM, 2009. Elaboración propia.

La expansión de las áreas regadas, la consolidación de aquéllas insuficientemente dotadas y la modernización de los existentes, generalmente mediante la adopción de tipologías de ahorro de agua son objetivos prioritarios de las políticas agrarias. Estas iniciativas han sido auspiciadas desde la administración central, pero también por las comunidades autónomas. Estas últimas desde principios de los noventa del pasado siglo, y especialmente, en aquéllas, donde la escasez de recursos es más acusada, patrocinaron iniciativas orientadas a favorecer la adopción de técnicas de manejo de agua entubada. La Comunidad Valenciana, la Región de Murcia y Andalucía, más concretamente, Almería, fueron pioneras en la introducción del riego por goteo, tanto en las nuevas roturaciones como en la sustitución de riegos tradicionales. La eficiencia y el ahorro fueron las causas que justificaron su adopción. El Inventario de Regadíos de Andalucía, publicado recientemente, refleja el proceso de expansión del olivar regado, pero, sobre todo de la modernización de regadíos. Se afirma que en 2008, con un $25 \%$ menos de agua que hace diez años y con los mismos recursos hídricos que había en 1997, se puede regar ahora un 35\% más de superficie. La provincia de Alicante en los últimos veinticinco años (1985-2009) habría modernizado unas 92.000 hectáreas de cultivos, lo que representa el $75 \%$ de la superficie regada provincial, lo que ha supuesto, según la Sociedad Estatal de Infraestructuras Agrarias (SEIASA), un ahorro de $83 \mathrm{hm}^{3}$ al año. En esta línea, el Informe Indicadores sobre el agua, 2004-2008 (INE, 2010) pone de manifiesto que los regadíos valencianos utilizan alrededor de $1.509 \mathrm{hm}^{3}$, es decir, un $10 \%$ del total nacional, lo que evidencia su intenso grado de modernización frente a los 2.178 de Aragón, 3.556 de Andalucía o los 1.561 de Castilla-La Mancha. Estos volúmenes se vinculan con la concentración de las superficies regadas en la Comunidad Autónoma de Andalucía, que acumula el $26 \%$ de los terrazgos irrigados (figura 3 ). Porcentajes a los que añadir el 14,7\% de Castilla-La Mancha, el 12,7\% de Aragón y el 9,2\% de la Comunidad Valenciana. Estos consumos no solo se relacionan con la entidad superficial del regadío, sino, sobre todo, con las modalidades de riego y los aprovechamientos practicados, que determinan dotaciones hídricas diversas. Cifras que adquieren una mayor trascendencia social y territorial si se tiene en cuenta que un tercio de las exportaciones agrícolas espanolas parte de la Comunidad Valenciana. 
La mejora y la consolidación de regadíos ha sido una de las actuaciones prioritarias llevadas a cabo por SEIASA desde 2001 y, con una intensidad mayor desde 2006 (tabla 5). Las iniciativas mayoritariamente se han orientado a la mejora de las infraestructuras para reducir pérdidas, especialmente en aquellos espacios regados con caudales superficiales, la consolidación de éstos y su modernización mediante la sustitución de sistemas de regadío por gravedad por los de manejo de agua (aspersión o goteo). La modernización y consolidación de regadíos tradicionales como los de las Vegas Altas de Murcia, el regadío deficitario de Lorca (Murcia) y del Vinalopó (Alicante), los abastecidos a través de canales (Aranda, Guma, Pisuerga, Arlanzón, Riaza, Júcar-Turia, entre otros) son ejemplos de las actuaciones llevadas a cabo por esta entidad. Minoritarias resultan en cambio las iniciativas orientadas a la obtención de caudales no convencionales, por ejemplo, mediante desalación o la mejora de regadíos en los que predominan ya los sistemas de manejo del agua como son dos iniciativas en Almería.

Tabla 5

ACTUACIONES DE INTERÉS GENERAL REALIZADAS POR SEIASA

\begin{tabular}{|l|r|r|r|r|r|}
\hline & $\begin{array}{c}\mathbf{N}^{\mathbf{0}} \text { proyectos } \\
\text { presentados }\end{array}$ & $\begin{array}{c}\mathbf{N}^{\mathbf{0}} \text { proyectos con } \\
\text { presupuesto }\end{array}$ & $\begin{array}{c}\text { Presupuesto } \\
(\mathbf{})\end{array}$ & $\begin{array}{c}\text { Superficie } \\
\text { (ha) }\end{array}$ & $\begin{array}{c}\mathbf{N}^{\mathbf{0}} \text { regantes } \\
\text { beneficiados }\end{array}$ \\
\hline Total & $\mathbf{2 9 8}$ & $\mathbf{1 9 7}$ & $\mathbf{2 . 2 5 9 . 4 8 6 . 6 6 4}$ & $\mathbf{7 8 1 . 7 7 7}$ & $\mathbf{2 7 1 . 0 1 3}$ \\
\hline Sur y Este & 88 & 27 & 410.110 .576 & 125.403 & 75.768 \\
\hline Meseta Sur & 68 & 68 & 671.054 .615 & 388.109 & 97.385 \\
\hline Norte & 85 & 45 & 583.587 .000 & 110.267 & 45.009 \\
\hline Nordeste & 57 & 57 & 594.734 .473 & 157.998 & 52.851 \\
\hline
\end{tabular}

Fuente: SEIASA, 2010. Elaboración propia.

\section{Los regadíos en los invernaderos y otros sistemas de cultivo protegido}

En la segunda mitad del siglo XX, cuando las producciones de las superficies hortícolas empiezan a tener un ritmo ascendente hacia los mercados europeos occidentales y centrales, acelerada esta progresión después de 1986, se contempla por parte de los agricultores, la necesidad del abastecimiento hortícola que tienen esos mercados desde otoño a primavera. Para atender esas demandas, sólo se contaban con las producciones de los pequeños huertos del sureste peninsular y de los piedemontes sureños béticos. Es entones, cuando, incluso agricultores foráneos, ven en los condicionantes del medio físico de esas comarcas las posibilidades de incrementar los cultivos hortícolas tradicionales e introducir otros nuevos del gusto de los consumidores europeos. Para ello, se hacen necesarias varias actuaciones. Primero, la ampliación de las superficies regadas mediante la captación de aguas subterráneas. Segundo, quebrar la inercia de los cultivadores locales, tanto ante la innovación tecnológica, como la de introducir nuevos cultivos. Tercero, agilizar los sistemas de comercialización con transportes rápidos. Cuarto, implantar sistemas de protección de los cultivos, que, de un lado, eviten los riesgos de helada y, de otro, contribuyan a aprovechar las más de 3.000 horas de luz anuales, sobre todo, en invierno, que caldean esos nuevos espacios de cultivos cubiertos y, que dada la buena luminosidad, aumenta la función clorofílica de las plantas, frente a lo que sucede en los invernaderos holandeses, que además de calefacción, necesitan luz artificial durante gran parte del día. 
Así, fue como a finales de la década de los sesenta del pasado siglo, se instalaron las primeras hectáreas de cultivo protegido con una estructura de madera y alambre, que sostenían una lámina de plástico, que la aislaba del exterior. Se conseguía, de esta forma, elevar de 5 a $8^{\circ} \mathrm{C}$ la temperatura interior respecto a la del aire libre. Con ello, se alcanzaba el óptimo térmico, diurno y nocturno, para que algunas hortalizas floreciesen y cuajasen los frutos en pleno invierno. Más tardíamente, década de los ochenta-noventa, se mejoraron las instalaciones con aporte de calor, $\mathrm{CO}_{2}$, ventilación asistida, estructuras metálicas y de plásticos endurecidos, insectos polinizadores y de lucha contra plagas, hidropónicos, etc. El lugar donde se produjo esta revalorización productiva agraria fue el Campo de Dalias, en la solana de la Sierra de Gádor (Almería). Desde allí, se irradió al resto del territorio mediterráneo español, con la salvedad de El Maresme (Barcelona), que había innovado simultáneamente. En 1996, la superficie de cultivos protegidos ascendía a 70.000 ha, de las cuales, más de la mitad, estaban en Almería y el Campo de Dalías. Tras Andalucía (50.116 hectáreas), eran la Región de Murcia y la Comunidad Valenciana, con 4.565 y 2.677 hectáreas respectivamente, las regiones con mayor superficie bajo plástico.

En los diez años transcurridos hasta 2007, último del que se dispone de estadísticas oficiales para todas las comunidades, el incremento con respecto a 1996, ha sido de unas 4.000 ha; situándose la superficie de cultivos protegidos alrededor de las 74.000 hectáreas (tabla 3). Esta desaceleración hay que interpretarla desde una perspectiva positivista, pues las producciones hortícolas se han incrementado en algunas variedades, mientras que otras se han abandonado. Lo primero es viable si se considera que las viejas estructuras de protección se han desmantelado y han dado paso a otros nuevos muy avanzados tecnológicamente, que permiten cosechar durante todo el año, caso de los tomates, u obtener dos cosechas anuales en los pimientos de la variedad california. De otro, se han abandonado algunos cultivos, judía verde, por ejemplo, que ahora no pueden competir con las procedentes del área de Agadir (Marruecos). En definitiva, se ha producido una reestructuración en el conjunto de los cultivos protegidos, pero mejorando rendimientos y calidades de los frutos obtenidos con mejores márgenes comerciales, en ocasiones.

La dinámica de los cultivos acolchados ha sido, en cambio, negativa en esta última década. Se trata de hortalizas que se adelantan de uno a dos meses respecto a las producidas al aire libre en el resto de Europa, por lo que consiguen una buena comercialización. Entre ellas, destacan algunas solanáceas (melones, sandías, pepinos) e, incluso, el fresón. Se ha pasado de 81.000 ha en 1997 a las 45.000 de 2007. Por regiones, la primera es Andalucía con 12.395 hectáreas, de las que unas 8.000 son las dedicadas al fresón en Huelva, seguida de Murcia con 8.300 ha. y Extremadura y Valencia con unas 3.900, cada una. El retraimiento en los cultivos acolchados en España hay que justificarlo en la fuerte competencia de las producciones de Marruecos y de otros países de la cuenca mediterránea.

Por último, los cultivos protegidos mediante malla térmica. Necesitan de estructuras metálicas de hasta cinco metros de altura, sobre las que descansa una malla de fibra plástica de unos dos milímetros, que ayuda a incrementar ligeramente la temperatura en el interior, pero, sobre todo, protege frente al granizo, aves e, incluso, de insectos. En caso de lluvia y viento, deja pasar a ambos y mantiene en el interior unas condiciones favorables para una mejor producción de los frutos y aumento de la efectividad de la lucha biológica contra las plagas. Así, se consiguen cosechas con menos residuos tóxicos y de más calidad de cara a los mercados. Los cultivos sobre los que se han implantado las mallas térmicas son algunas variedades de cítricos, sobre todo mandarinos, y melocotoneros, perales, manzanos, níspero, uva de mesa, aguacates, etc. Todavía no se dispone de una estadística que refleje claramente su utilización, pero empiezan a proliferar en la citricultura valenciana y murciana, parrales de Murcia, níspero de Alicante, cerezas de Extremadura y prunus y rosáceas de Aragón y Cataluña. 


\section{Conclusión}

Los regadíos españoles han continuado incrementando su superficie en las primeras décadas del siglo XXI. La tendencia alcista presenta, sin embargo, diferencias significativas desde el punto de vista de los aprovechamientos y los sistemas de regadío. Los cultivos que han registrado sus mayores aumentos son viñedo y olivar, es decir, aquéllos tradicionalmente de secano, frente a cultivos asociados secularmente al regadío, como hortalizas y frutales (cítricos o prunus), que presentan unas dinámicas más contenidas, cuando no regresivas. No obstante, la ampliación de la superficie en regadío en viñedo y olivar no aparece reflejada en su totalidad en las estadísticas oficiales, cuando es más que evidente su expansión en los últimos veinte años. Las causas de este enmascaramiento se vinculan a procesos relacionados con las concesiones de agua, las exigencias de los estatutos reguladores de algunas denominaciones de origen, entre otras. Las ayudas procedentes de la PAC resultan fundamentales para entender el mantenimiento de las superficies de los regadíos extensivos (cereales y cultivos industriales), pero también la fuerte expansión que ha protagonizado el olivar o el viñedo. En este último, los excedentes son absorbidos, en parte, mediante la compra de alcohol para destilaciones obligatorias, ayudas al almacenamiento privado de vinos y mostos y arranque de superficies. Se producen, por tanto, contradicciones en las actuaciones de planificación pública entre el manejo de los recursos hídricos disponibles y su utilización para expandir cultivos de escasas repercusiones socio-económicas. Lo cierto es que, mientras se discute o se ignora qué actuación sobre el agua y productividad sería la más adecuada, se están sobreexplotando acuíferos, consumiendo energía en abundancia y dejando sin solucionar el éxodo rural de algunas comarcas. La expansión de las superficies regadas se caracteriza por otro elemento, como es la difusión que han registrado los sistemas de manejo de agua. El riego localizado ha registrado un importante crecimiento; vinculado el primero a la conversión en regadío de olivares y viñedos. Su introducción se relaciona, asimismo, con las actuaciones de modernización y consolidación de regadíos auspiciadas desde las administraciones públicas. Siendo uno de los objetivos esgrimidos en su difusión el ahorro de recurso y su mayor eficiencia.

El cambio en la valoración del agua como recurso, los intensos procesos de pérdida de calidad tanto por contaminación como por sobreexplotación de acuíferos, los incrementos en la demanda, agrícola pero, especialmente, urbana, la implantación de la nueva Directiva Marco del Agua son algunos de los factores que han conducido hacia la adopción de iniciativas orientadas, al menos desde una óptica teórica, hacia la sostenibilidad de las políticas que giran en torno al agua. El regadío, principal consumidor de este recurso en España, no podía ser una excepción. Desde finales del siglo XX, la política de regadíos ha apostado por actuaciones orientadas a la garantía de disponibilidad y calidad del recurso, consumo sostenible y eficiente o el uso de los recursos no convencionales. Mediante el Real Decreto 287/2006, por el que se regulan las obras urgentes de mejora y consolidación de regadios, conocido como Plan de Choque, se han ejecutado un conjunto de actuaciones de modernización de regadíos, con el fin de maximizar el ahorro de agua para paliar los efectos de la sequía padecida en los años 2004 y 2005, así como orientar el Plan Nacional de Regadíos a la nueva Directiva Marco del Agua (tabla 5). El impulso a la modernización de regadíos, a través del fomento del ahorro y mejora de la eficiencia en el uso del agua, la transferencia de tecnología al sector del riego, la utilización de recursos hídricos alternativos, la mejora de la renta agraria y el desarrollo rural y, en definitiva, una agricultura sostenible y respetuosa con el medio ambiente son las directrices básicas de la Estrategia Nacional para la Modernización Sostenible de los Regadios. Horizonte 2015, presentado 
a las comunidades autónomas a finales de 2009. Su objetivo es continuar las actuaciones anteriores orientadas a la modernización de las instalaciones de riego de menor eficiencia hídrica, mejorando la gestión del agua y promoviendo la sostenibilidad del sector, sin caer en las contradicciones señaladas en la introducción.

\section{Bibliografía}

ARAQUE JIMÉNEZ, E. (2007): «Luces y sombras de la expansión olivarera en Sierra Mágina». En: Sumantan: anuario de estudios sobre Sierra Mágina, $\mathrm{n}^{\circ}$ 25, pp. 65-96.

BARAJA RODRÍGUEZ, E. y MOLINERO HERNANDO, F. (2008): «Nueva dinámica de los paisajes de regadío en el Duero». En: Los paisajes rurales españoles en el nuevo siglo. Actas XIV Congreso de Geografía Rural. Murcia, Asociación de Geógrafos Españoles, pp. 97-100.

GÓMEZ ESPÍN, J.Mª .; GARCÍA MARIN, R. y GIL MESEGUER, E. (2007): «Modernización de regadíos con aguas subterráneas en ámbitos semiáridos». En: $M+A$, revista electrónica de medio ambiente, $\mathrm{n}^{\circ} 3$.

GÓMEZ ESPÍN, J.Mª; GARCÍA MARÍN, R. y GIL MESEGUER, E. (2005): «Insuficiencias hídricas y modernización de regadíos en la cuenca del Mula». En: Papeles de Geografía, no 41-42, pp. 101-122.

MOLINERO HERNANDO, F. (2006): «La evolución de la agricultura en España: tradición, modernización y perspectivas». En: Norba. Revista de Geografía, n 11, pp. 85-106.

MOLINERO HERNANDO, F. y BARAJA, E. (2008): «El aprovechamiento de los regadíos de Castilla y León durante veinte años de la PAC». En: Las agriculturas españolas y la política agraria comunitaria: veinte años después. Jaén, Universidad Internacional de Andalucía, pp. 203-224.

MORALES GIL, A. (1997): Aspectos geográficos de la horticultura de ciclo manipulado en España. Alicante, Universidad de Alicante, $167 \mathrm{pp}$.

MORALES GIL, A. (1999): «El consumo agrícola de agua. Sus modalidades y trascendencia socioeconómica actual». En: Los usos del agua en España. Alicante, Caja de Ahorros del Mediterráneo e Instituto Universitario de Geografía, pp. 49-78.

MORALES GIL, A. (2001): «Reestructuración espacial y cualitativa reciente del viñedo en la región de Murcia». En: Espacio natural y dinámicas territoriales. Homenaje al Dr. Jesús García Fernández. Valladolid, Universidad de Valladolid, pp. 503-514.

PIQUERAS HABA, J. (1998): «Cambios recientes en el sector vitícola valenciano (1977-1997): En: Cuadernos de Geografía, no 63, pp. 177-194.

PIQUERAS HABA, J. (2008): «El sector vitivinícola español y la PAC 1986-2005: del optimismo a la crisis». En: Las agriculturas españolas y la política agraria comunitaria: veinte años después. Jaén, Universidad Internacional de Andalucía, pp. 307-324.

RICO AMORÓS, A.M. y HERNÁNDEZ HERNÁNDEZ, M. (2008): «El sector agrario español y su adaptación a la política agraria comunitaria en los últimos veinte años». En: Las agriculturas españolas y la política agraria comunitaria: veinte años después. Jaén, Universidad Internacional de Andalucía, pp. 15-43.

RUIZ PULPÓN, A.R. (2008): «La superficie de regadío en la cuenca del río Guadiana en Castilla-La Mancha: nuevos usos del suelo y agravamiento de los problemas ambientales». En: Las agriculturas españolas y la política agraria comunitaria: veinte años después. Jaén, Universidad Internacional de Andalucía, pp. 337-350.

RUIZ PULPÓN, A.R. (2010): «Evolución y consolidación del viñedo de regadío en La Mancha». En: Boletín de la Asociación de Geógrafos Españoles, no 52, pp. 5-26.

SÁNCHEZ MARTÍNEZ, J.D.; GALLEGO SIMÓN, J.D. y ARAQUE JIMÉNEZ. E. (2008): «El monocultivo olivarero jienense: ¿del productivismo a la sostenibilidad?. En: Boletín de la Asociación de Geógrafos Españoles, $\mathrm{n}^{\circ}$ 47, pp. 245-270.

SILVA PÉREZ, R. y MORAL ITUARTE, L. del (2005): «Nuevas dinámicas socioeconómicas y alternativas de desarrollo territorial: el caso de la zona regable del Bajo Guadalquivir». En: Boletín de la Asociación de Geógrafos Españoles, nº 40, pp. 223-244. 


\section{Fuentes estadísticas}

CONSELLERIA DE AGRICULTURA, PESCA y ALIMENTACION (Generalitat Valenciana): Datos básicos del sector agrario valenciano. Varios años. Disponible en: http://www.agricultura.gva. es/publicaciones/revistasint.php?id $=6 \&$ comu $=$

CONFEDERACIÓN HIDROGRÁFICA DEL JÚCAR, Esquema provisional de temas importantes de la Demarcación Hidrográfica del Júcar, 2008. Disponible en: http://www.phjucar.com/docs/ cons_publica/iniciales/ETI-Ed62.pdf

CONFEDERACIÓN HIDROGRÁFICA DEL GUADIANA, Esquema provisional de temas importantes de la parte española de la Demarcación Hidrográfica del Guadiana, 2008. Disponible en: http://planhidrologico2009.chguadiana.es/

CONSERJERÍA DE AGRICULTURA Y PESCA (Junta de Andalucía): El sector del aceite de oliva y de la aceituna de mesa en Andalucía, 2008. Disponible en: http://www.juntadeandalucia.es/ agriculturaypesca/portal/servicios/estadisticas/estudios-e-informes/agricultura/olivar/sector-aceiteaceituna-mesa-andalucia.html

CENTRO REGIONAL DE ESTADÍSTICA DE MURCIA (CREM): Datos básicos de la región de Murcia, 2008. Disponible en http://www.carm.es/econet/sicrem/PU\%5FdatosBasicos/Indice5.html

FEGA (2010): Informes sobre la financiación de la PAC en España. Varios años. Disponible en: http://www.fega.es/PwfGcp/es/accesos_directos/informes/index.jsp

GOBIERNO DE ARAGÓN, Anuario de estadística agraria. Varios años. Disponible en:http://portal. aragon.es/portal/page/portal/AGR/ESTADISTICAS_AGRICOLAS_GANADERAS/Anuarios

INSTITUTO NACIONAL DE ESTADÍSTICA(INE): Indicadores sobre agua 2004-2008. Disponible en: http://www.ine.es/jaxi/menu.do?type=pcaxis\&path=/t26/p069/p03/\&file=pcaxis

INSTITUTO DE ESTADÍSTICA DE CASTILLA-LA MANCHA (IES) Encuesta sobre el uso del agua en el sector agrario. Varios años. Disponible en: http://difusion.ies.jccm.es/wds/ReportFolders/ReportFolders.aspx

INSTITUTO DE ESTADÍSTICA DE CASTILLA-LA MANCHA (IES), Anuario Estadístico de Castilla La Mancha, 2008. Disponible en: http://www.ies.jccm.es/Publicaciones/Anuario_2008.pdf

JUNTA DE ANDALUCÍA, Anuario de Estadística Agraria y pesquera de Andalucía. Varios años. Disponible en: http://www.juntadeandalucia.es/agriculturaypesca/portal/servicios/estadisticas/ estadisticas/agrarias/resumen-anual.html

JUNTA DE CASTILLA Y LEÓN, Anuario de Estadística Agraria. Varios Años. Disponible en: http:// www.jcyl.es/web/jcyl/AgriculturaGanaderia/es/Plantilla66y33/1131977261144/_/__

MINISTERIO DE AGRICULTURA, PESCA Y ALIMENTACIÓN (MAPA): Anuario de Estadística, 1999. Disponible en: http://www.mapa.es/estadistica/pags/anuario/1999/index2.htm

MINISTERIO DE AGRICULTURA, PESCA Y ALIMENTACIÓN (MAPA) (2003): Plan Nacional de Regadío. Horizonte 2008. Disponible en: http://aplicaciones.mapa.es/es/desarrollo/pags/pnr/ principal.htm

MINISTERIO DE MEDIO AMBIENTE Y MEDIO RURAL Y MARINO (MARM): Anuario de Estadística, 2008. Madrid. Disponible en: http://www.mapa.es/es/estadistica/pags/anuario/2008/ indice.asp

MINISTERIO DE MEDIO AMBIENTE Y MEDIO RURAL Y MARINO (MARM): Encuesta sobre superficies y rendimientos de cultivos, 2009 (ESYRCE). Madrid. Disponible en: http://www.mapa. es/es/estadistica/pags/EncuestaCultivos/resultados.htm

REGIÓN DE MURCIA (CARM): Estadística Agraria Regional. Varios años. Disponible en: http:// www.carm.es

SOCIEDAD ESTATAL DE INFRAESTRUCTURAS AGRARIAS (SEIASA): Obras de interés general. Disponible en: http://www.mapa.es/seiasa/seiasa.htm 
